\title{
Effectiveness of Fibers from "Cabernet Sauvignon" (Vitis vinifera) Pomace as Fining Agents for Red Wines
}

\author{
Mariona Gil (D), ${ }^{1,2}$ Rubén Del Barrio-Galán, ${ }^{1}$ Cristina Úbeda, ${ }^{3}$ and Álvaro Peña-Neira ${ }^{1}$ \\ ${ }^{1}$ Department of Agro-Industry and Enology, Faculty of Agronomical Sciences, University of Chile, P.O. Box 1004, Santiago, Chile \\ ${ }^{2}$ Universidad Autónoma de Chile, Instituto de Ciencias Químicas Aplicadas, Inorganic Chemistry and Molecular Materials \\ Center, El Llano Subercaseaux 2801, San Miguel, Santiago, Chile \\ ${ }^{3}$ Instituto de Ciencias Biomédicas, Facultad de Ciencias de la Salud, Universidad Autónoma de Chile, Providencia, Chile \\ Correspondence should be addressed to Mariona Gil; mariona.gil@uautonoma.cl
}

Received 18 December 2017; Revised 2 April 2018; Accepted 18 April 2018; Published 9 May 2018

Academic Editor: Encarnación Gómez-Plaza

Copyright (C) 2018 Mariona Gil et al. This is an open access article distributed under the Creative Commons Attribution License, which permits unrestricted use, distribution, and reproduction in any medium, provided the original work is properly cited.

\begin{abstract}
Recent findings have highlighted the potential of fibers from grape cell wall material to be fining agents for red wines as alternatives to animal-derived proteins. The affinity of those fibers for grape proanthocyanidins (also known as condensed tannins) seems to depend on the initial phenolic composition of the wines to be fined and on the applied dose of fibers. In the present work, "Cabernet Sauvignon" grapes were harvested at three different maturity levels and used for making red wine. The pomaces of the three vinifications were used to obtain the cell wall fibers. Each wine was treated with the three purified fibers at two different doses $(0.2 \mathrm{~g} / \mathrm{L}$ and $2.5 \mathrm{~g} / \mathrm{L})$ under winery-like conditions in order to check the potential of fibers as fining agents. Color and phenolic composition of the treated wines were determined immediately after the treatments and after four and nine months of wine bottle ageing. The effectiveness of the fining strongly depends on the initial wine matrix. Wines treated at high doses had lower color density and higher hue than control untreated wines. Small differences were observed in the phenolic content of the treated wines. Those differences were dose dependent and almost disappeared after several months of ageing. The maturity of the grapes from which the fibers came had no influence on the effectiveness of the fining. Additionally, there was no evidence of polysaccharide release from the fibers to the wine.
\end{abstract}

\section{Introduction}

The interest in grape cell walls has considerably increased in recent years, and it has become one of the main topics of oenological research. The interactions between cell walls and phenolic compounds have several implications for the phenolic extractability of grape skins throughout ripening and during winemaking [1-7]. Moreover, due to these interactions, several authors have highlighted the potential use of cell wall materials as fining agents for red wines [5, 8-10].

Fining agents are adsorptive compounds used by winemakers to partially remove soluble compounds from the wine in order to modify its sensory features (such as astringency, bitterness, and mouthfeel) and ageing capacity. Traditionally, the most commonly used fining agents in the oenological industry are animal-derived proteins (such as albumin, isinglass, casein, and gelatin) [11], but consumers have generated some reticence about the use of these products for winemaking recently due to public health concerns (related to the allergenic potential of animal proteins). Thus, the wine industry began to look for vegetable-derived fining agents as alternatives for the traditional animal-derived fining agents $[9,12]$.

Using grape cell wall fibers for wine fining could have many advantages. Firstly, their grape origin avoids the consumers' concerns about healthfulness. Furthermore, the great amount of cell wall material in grape pomace allows winemakers to obtain a valuable product from winery waste, which leads to greater sustainability in the wine industry itself.

Most of the current literature on the use of grape-derived fibers for wine fining is based on interaction studies between 
cell walls and tannins using synthetic wine-like solutions with purified or commercial tannins $[1,8,9,13,14]$. To our knowledge, the only study that used real wine for fining trials with grape-derived fibers was performed under laboratory conditions using a very small volume of wine, high doses of fibers, and a laboratory centrifuge to remove the solids after treatment [10]. In the present work, we perform fining trials with grape pomace-derived fibers under winery-like conditions, applying the fibers into the wines at two different doses $(0.2 \mathrm{~g} / \mathrm{L}$ and $2.5 \mathrm{~g} / \mathrm{L}$ : the first one being a reasonable dose in winery conditions compared with the commercially available fining agents commonly used, and the second one more comparable with doses applied in laboratory trials found in the literature), and let them naturally settle before racking and bottling the wine. Moreover, to check the potential of grape pomace-derived fibers, three wines with different phenolic compositions obtained from grapes harvested at three different maturity levels were used for the fining trials. The grape pomaces of the three vinifications were used for obtaining the fibers in order to observe the influence of grape maturity and fiber production on fining effectiveness. Finally, the wines were characterized immediately after fining treatments and after four and nine months of bottle ageing to check the influence of the fining throughout wine ageing.

\section{Materials and Methods}

2.1. Chemicals and Equipment. Sodium hydroxide, acetaldehyde, phloroglucinol, L-ascorbic acid, ammonium formate (for HPLC $\geq 99 \%$ ), (-)-epicatechin analytical standard (for proanthocyanidin analysis, external standard calibration), pectin from citrus fruit (for polysaccharide analysis, external standard calibration), and nine analytical standards for size exclusion chromatography (SEC) of dextrans from Leuconostoc mesenteroides (used for SEC column calibration) were purchased from Sigma-Aldrich (Sigma-Aldrich Co., St. Louis, MO). Acetone, sodium disulfite, hydrochloric acid fuming (37\%), ethanol absolute, methanol (gradient grade for liquid chromatography), and acetic acid (glacial) were purchased from Merck (Merck KGaA, Darmstadt, Germany). Potassium disulfite was purchased from Droguería Michelson (Drogueria Michelson, Santiago de Chile, Chile). A handheld refractometer, QUIMIS, was used for total soluble solid determination. The water purification system PURELAB Ultra (Elga Labwater, Arquimed, Santiago de Chile, Chile) was used for water purification. $\mathrm{pH}$ measurements were performed with an S220 SevenCompact $\mathrm{pH} /$ Ion Mettler Toledo $\mathrm{pH}$ meter (Mettler-Toledo Intl. Inc., Columbus, OH). Pomace homogenization was performed using an Ultra-Turrax T-25 basic (Ika-Werke, Staufen, Germany). A thermostatized bath MEMMERT WB 22 (Memmert GmbH + Co KG, Lab-Tec Ltda., Santiago de Chile, Chile) was used for cell wall purification and to perform the phloroglucinolysis reaction. Centrifugations were performed in a Heraeus Labofuge 400 Function Line (Thermo Fisher Scientific Inc., Waltham, MA). All of the spectrophotometric measurements were performed with a UV-Vis spectrophotometer SHIMADZU UV-1700
TABLE 1: Maturity controls of the grapes used for winemaking: general parameters of the finished wines.

\begin{tabular}{ccccc}
\hline & & Unripe & Mature & Overripe \\
\hline \multirow{4}{*}{ Grapes } & Harvest & & & \\
& date & February 27 & March 17 & April 10 \\
& TSS $^{\mathrm{a}}$ & $21.33 \pm 0.12 \mathrm{a}$ & $24.23 \pm 0.12 \mathrm{~b}$ & $26.83 \pm 0.06 \mathrm{c}$ \\
& $\mathrm{TA}(\mathrm{g} / \mathrm{L})^{\mathrm{b}}$ & $9.4 \pm 0.1 \mathrm{c}$ & $7.9 \pm 0.1 \mathrm{~b}$ & $6.5 \pm 0.1 \mathrm{a}$ \\
& $\mathrm{pH}$ & $3.13 \pm 0.01 \mathrm{a}$ & $3.27 \pm 0.02 \mathrm{~b}$ & $3.47 \pm 0.01 \mathrm{c}$ \\
\hline \multirow{4}{*}{ Wines } & $\%(\mathrm{v} / \mathrm{v})$ & $10.7 \pm 0.1 \mathrm{a}$ & $14.4 \pm 0.2 \mathrm{~b}$ & $16.2 \pm 0.1 \mathrm{c}$ \\
& $\mathrm{TA}(\mathrm{g} / \mathrm{L})^{\mathrm{b}}$ & $6.4 \pm 0.2 \mathrm{c}$ & $5.4 \pm 0.1 \mathrm{~b}$ & $5.0 \pm 0.1 \mathrm{a}$ \\
& $\mathrm{pH}$ & $3.41 \pm 0.01 \mathrm{a}$ & $3.73 \pm 0.01 \mathrm{~b}$ & $3.82 \pm 0.01 \mathrm{c}$ \\
\hline
\end{tabular}

Note. ${ }^{\text {a }}$ Total soluble solids expressed as Brix degrees. ${ }^{\mathrm{b}}$ Titratable acidity expressed as tartaric acid equivalents. Different letters in a row indicate statistical differences $(p<0.05)$ among samples.

PharmaSpec (Equilab Ltda., Santiago de Chile, Chile). Evaporation of samples for proanthocyanidin and polysaccharide analyses was performed with a centrivap concentrator, LABCONCO (LABCONCO Corporation, Kansas City, MI), coupled to a vacuubrand MD 4C NT vacuum pump (Vacuubrand, Wertheim, Germany). High-performance size exclusion chromatography-refractive index detection (HPSEC-RID) of soluble polysaccharides was performed with two Shodex OHpak SB-803 HQ and SB-804 HQ columns connected in series (300 $\mathrm{mm} \times 8 \mathrm{~mm}$ I.D; Showa Denko, Japan) and using an Agilent 1260 Infinity Series liquid chromatograph (Agilent Technologies, Santa Clara, CA) equipped with a G1329A autosampler, a G1311B quaternary pump, a G1316A column oven, a G1362A refractive index detector, and a G1315D diode array detector. Polysaccharide samples were freeze-dried with an FD5508 Floor-Model Freeze dryer IlShin BioBase (Ilshin Biobase Co., LTD., Yangju-gun, South Korea). For the analysis of the adducts after the acidic depolymerization of proanthocyanidin in the presence of an excess of phloroglucinol, am Agilent 1200 Series chromatograph (Agilent Technologies, Santa Clara, CA) equipped with a G1322A degasser, a G1311A quaternary pump, a G1329A autosampler, a G1316A column oven, and a G1315B diode array detector was used. Both chromatographs were coupled to an Agilent ChemStation (version B.04.03) data-processing station.

2.2. Grapes and Wines. The experiment was carried out with grapes of the Vitis vinifera "Cabernet Sauvignon" grapevine self-rooted from Emiliana Vineyards (Cachapoal Valley, Chile; $34^{\circ} 20^{\prime} 13.1^{\prime \prime}(\mathrm{S})$ and $70^{\circ} 45^{\prime} 50.8^{\prime \prime}(\mathrm{W})$ ) during the 2015 vintage. The grapevines were trained on a vertical trellis system, arranged in rows spaced $2.0 \mathrm{~m}$ apart, with $1.0 \mathrm{~m}$ between plants in the row, and equipped with a drip irrigation system. The harvested grapes for the experiment come from around 300 vines selected from the middle of three consecutive rows located in a homogeneous soil zone (loamy soil type) in the vineyard. Grapes were harvested manually at three different maturity levels as indicated in Table 1 . The analytical methods recommended by the International Organization of Vine and Wine (OIV) were used to determine the sugar concentration, $\mathrm{pH}$, and titratable acidity of the grapes [15] as well as alcoholic degree, $\mathrm{pH}$, and 
titratable acidity of the wines. Approximately $150 \mathrm{~kg}$ of grapes was harvested for each maturity level and transported to the Department of Agro-Industry and Enology of the University of Chile in $20 \mathrm{~kg}$ plastic boxes. Grapes were destemmed, crushed, sulfited $\left(100 \mathrm{mg} \cdot \mathrm{K}_{2} \mathrm{~S}_{2} \mathrm{O}_{5} / \mathrm{kg}\right)$, and placed in stainless steel tanks. The tanks were immediately inoculated with $200 \mathrm{mg} / \mathrm{kg}$ of selected Saccharomyces cerevisiae yeast (Lalvin ${ }^{\circledR}$ EC1118, Lallemand Inc., Montreal, Canada). The alcoholic fermentation was controlled daily by measuring the temperature and the density of the juice. The cap was gently punched down daily in order to improve phenolic extraction. After 2 weeks of maceration, when the alcoholic fermentation was finished, the wines from the tanks were racked, slightly sulfited $\left(25 \mathrm{mg} \cdot \mathrm{K}_{2} \mathrm{~S}_{2} \mathrm{O}_{5} / \mathrm{kg}\right)$, and kept at $1^{\circ} \mathrm{C}$ for 10 days for tartaric stabilization. Then, the wines were tempered around $18^{\circ} \mathrm{C}$ and inoculated with $10 \mathrm{mg} / \mathrm{L}$ of selected Oenococcus oeni lactic acid bacteria (Lalvin VP41 ${ }^{\circledR}$, Lallemand Inc., Montreal, Canada). The malolactic fermentation was monitored by paper chromatography [16]. Once the malolactic fermentation was over, the wines were sulfited $\left(100 \mathrm{mg} \cdot \mathrm{K}_{2} \mathrm{~S}_{2} \mathrm{O}_{5} / \mathrm{kg}\right)$ and maintained in stainless steel tanks $(100 \mathrm{~L})$ until wine treatment.

2.3. Obtaining the Cell Wall Fibers from Grape Pomace. When the wines were racked after alcoholic fermentation, around $10 \mathrm{~kg}$ of grape pomace from each harvest was recovered, distributed in lots of $1 \mathrm{~kg}$ each, frozen, and maintained at $-20^{\circ} \mathrm{C}$ until cell wall isolation. The grape pomace was thawed in the cold $\left(4^{\circ} \mathrm{C}\right)$, and the seeds were manually removed before the cell wall isolation process. Cell wall isolation corresponds to the alcohol insoluble residues (AIRs) obtained by the Vries method previously described in the literature [17].

2.4. Wine Treatments. For each wine class, 6 different treatments with grape pomace fibers were applied in triplicate: a low dose (dose 1: $0.2 \mathrm{~g} / \mathrm{L}$ ) and a high dose (dose 2: $2.5 \mathrm{~g} / \mathrm{L}$ ) of the isolated fibers from the three pomaces (those from unripe, mature, and overripe grape pomaces). An untreated triplicate was processed in the same way and used as a control. Wine fiber dosages were given in $3.5 \mathrm{~L}$ containers for 3 days and stirred daily. After the treatment period, the wines were racked in order to remove the insoluble fibers, bottled in $0.75 \mathrm{~L}$ green glass bottles, capped with natural corks of flor quality, $49 \times 24 \mathrm{~mm}$ (Corpack Bourrasse S.A., Santiago de Chile, Chile), and stored in a dark cellar in a horizontal position at $16^{\circ} \mathrm{C}$ until analysis.

2.5. Wine Analysis. Wines were analyzed immediately after the treatment and after 4 and 9 months of bottle storage. All wine samples were centrifuged ( $12500 \mathrm{~g}$ for 20 minutes) before analysis. Twenty microliters of an aqueous solution of acetaldehyde (10\%) was added to $2 \mathrm{~mL}$ of wine 45 minutes before color measurements in order to avoid sulfite effects. Color intensity (CI) and hue $(T)$ were determined as described in the literature [18]. CIELab coordinates of the wines were determined by measuring the absorbance at
$450 \mathrm{~nm}, 520 \mathrm{~nm}, 570 \mathrm{~nm}$, and $630 \mathrm{~nm}$ with a quartz cuvette (path length $1 \mathrm{~mm}$ ) and using $\mathrm{MSCV}^{\circledR}$ software for computing absorbance data [19]. The phenolic index $\left(\mathrm{I}_{280}\right)$ and total anthocyanin content were determined as previously described [18]. Proanthocyanidins were extracted from wine as previously described [20]. After their extraction, proanthocyanidin analysis was performed by RP-HPLC-DAD analysis of adducts formed after an acidic depolymerization of proanthocyanidins in the presence of an excess of phloroglucinol [21] (phloroglucinolysis) using a LiChrospher 100 RP-18 endcapped $(5 \mu \mathrm{m})$ Hibar RT 2504.6 HPLC column (Merck KGaA, Darmstadt, Germany). The polysaccharide content of the wines was estimated by precipitation with cold acidified ethanol and analyzed by HRSEC-RID as previously described [22].

2.6. Statistical Analysis. All data are expressed as the arithmetic average \pm standard deviation of three replicates. Principal component analysis (PCA) and one-factor analysis of variance tests $(p<0.05)$ were conducted with SPSS software (IBM, Barcelona, Spain), and multiple comparisons were tested with the Student-Newman-Keuls post hoc test. The spectrophotometric data used for the PCA included color intensity, hue, blue, red, and yellow components, CIELab coordinates and their ratios, total phenolic content, total anthocyanin content, the percentage of the color due to the free and combined anthocyanins described by Glories (dA) [23], the Kerenyi and Kampis Index (K-K) [24], and the chemical ageing $\left(\mathrm{CA}_{\mathrm{II}}\right.$, which corresponds to the proportion of total pigment color due to polymeric pigments) [25].

\section{Results and Discussion}

3.1. Wine Phenolics. Table 1 shows the general parameters of grape juices and wines. As could be expected, grapes from each harvest date show different technological maturity (explained by the increasing trend for soluble solids and $\mathrm{pH}$ and the decreasing trend for titratable acidity). Obviously, the different technological maturity of grapes leads to wines with increasing alcoholic content $(\% \mathrm{v} / \mathrm{v})$. The phenolic index $\left(\mathrm{I}_{280}\right)$ shown in Table 2 indicates the total phenolic content of the wines. As could be expected, grape maturity strongly influenced the phenolic content of the wines: the riper the grapes, the higher the wine phenolic content. These data agree with previously published data $[26,27]$ and demonstrate that the three treated wines are quite distinct in terms of phenolic content, either due to differences in the phenolic maturity of the grapes or due to extraction differences caused by the wine alcohol content. Regardless of the treatment, a general trend could be observed that the longer the bottle ageing, the lower was the $I_{280}$ for all of the wines. A reduction in total phenolic content during bottle ageing has been previously described and has been related to the degradation (oxidation) of some phenolic compounds with some rearrangement (affecting mainly proanthocyanidins and anthocyanins) that leads to highmolecular-weight polymers that could precipitate [28, 29]. Immediately after the treatment ( 0 months ageing), the 
TABle 2: Phenolic index $\left(\mathrm{I}_{280}\right)$ of the wines.

\begin{tabular}{|c|c|c|c|c|c|}
\hline & & & 0 months aged & 4 months aged & 9 months aged \\
\hline \multirow{7}{*}{ Unripe wine } & \multirow{4}{*}{ Dose 1} & Control & $39.65 \pm 0.26 \mathrm{~d} \beta$ & $38.13 \pm 0.28 \mathrm{c} \alpha$ & $37.68 \pm 0.28 \mathrm{~b} \alpha$ \\
\hline & & Unripe fibers & $38.50 \pm 0.78$ abc $\beta$ & $37.75 \pm 0.09 \mathrm{bc} \alpha$ & $37.64 \pm 0.12 \mathrm{~b} \alpha$ \\
\hline & & Mature fibers & $39.28 \pm 0.37 \mathrm{~cd} \beta$ & $37.94 \pm 0.52 \mathrm{bc} \alpha$ & $37.20 \pm 0.54 \mathrm{ab} \alpha$ \\
\hline & & Overripe fibers & $39.04 \pm 0.39 \mathrm{bcd} \beta$ & $36.77 \pm 0.26 \mathrm{bc} \alpha$ & $37.14 \pm 0.71 \mathrm{ab} \alpha$ \\
\hline & \multirow{3}{*}{ Dose 2} & Unripe fibers & $37.93 \pm 0.49$ a $\beta$ & $37.72 \pm 0.20 \mathrm{ab} \beta$ & $36.20 \pm 0.58 \mathrm{ab} \alpha$ \\
\hline & & Mature fibers & $37.92 \pm 0.19$ a $\gamma$ & $37.30 \pm 0.33$ a $\beta$ & $35.78 \pm 0.63$ a $\alpha$ \\
\hline & & Overripe fibers & $38.16 \pm 0.09 \mathrm{ab} \beta$ & $37.36 \pm 0.26 \mathrm{ab} \alpha \beta$ & $36.71 \pm 0.81 \mathrm{ab} \alpha$ \\
\hline \multirow{7}{*}{ Mature wine } & \multirow{5}{*}{ Dose 1} & Control & $51.68 \pm 0.85$ a $\beta$ & $47.13 \pm 0.75$ a $\alpha$ & $48.18 \pm 1.75$ a $\alpha$ \\
\hline & & Unripe fibers & $51.53 \pm 0.08$ a $\beta$ & $47.69 \pm 1.12$ a $\alpha$ & $47.33 \pm 0.40$ a $\alpha$ \\
\hline & & Mature fibers & $51.01 \pm 0.73$ a $\beta$ & $48.22 \pm 0.87$ a $\alpha$ & $47.17 \pm 0.31$ a $\alpha$ \\
\hline & & Overripe fibers & $50.89 \pm 0.06$ a $\gamma$ & $47.28 \pm 0.96$ a $\beta$ & $46.94 \pm 0.18$ a $\alpha$ \\
\hline & & Unripe fibers & $50.91 \pm 0.62$ a $\beta$ & $48.07 \pm 0.61$ a $\alpha$ & $46.89 \pm 0.82$ a $\alpha$ \\
\hline & \multirow[t]{2}{*}{ Dose 2} & Mature fibers & $50.70 \pm 0.92$ a $\beta$ & $47.55 \pm 1.16$ a $\alpha$ & $47.19 \pm 0.14$ a $\alpha$ \\
\hline & & Overripe fibers & $51.09 \pm 0.52$ a $\beta$ & $47.72 \pm 0.92$ a $\alpha$ & $47.67 \pm 0.07$ a $\alpha$ \\
\hline \multirow{7}{*}{ Overripe wine } & \multirow{5}{*}{ Dose 1} & Control & $58.94 \pm 1.35$ b $\beta$ & $52.73 \pm 0.52$ a $\alpha$ & $52.73 \pm 0.68$ a $\alpha$ \\
\hline & & Unripe fibers & $59.13 \pm 0.47 \mathrm{~b} \beta$ & $53.77 \pm 0.68$ a $\alpha$ & $52.83 \pm 0.10$ a $\alpha$ \\
\hline & & Mature fibers & $59.22 \pm 0.40 \mathrm{~b} \gamma$ & $54.04 \pm 1.01$ a $\beta$ & $52.76 \pm 0.66$ a $\alpha$ \\
\hline & & Overripe fibers & $58.72 \pm 0.27 \mathrm{~b} \beta$ & $53.69 \pm 0.68$ a $\alpha$ & $53.15 \pm 0.72$ a $\alpha$ \\
\hline & & Unripe fibers & $57.52 \pm 0.09$ a $\beta$ & $54.30 \pm 1.04$ a $\alpha$ & $52.85 \pm 0.58$ a $\alpha$ \\
\hline & \multirow[t]{2}{*}{ Dose 2} & Mature fibers & $57.00 \pm 0.45$ a $\gamma$ & $53.35 \pm 0.92$ a $\beta$ & $51.98 \pm 0.41$ a $\alpha$ \\
\hline & & Overripe fibers & $56.79 \pm 0.55$ a $\beta$ & $54.08 \pm 0.95$ a $\alpha$ & $52.85 \pm 0.85$ a $\alpha$ \\
\hline
\end{tabular}

Note. Different letters in a column show statistical differences $(p<0.05)$ among treatments within each wine class. Different Greek letters in a row indicate statistical differences $(p<0.05)$ among bottle ageing times.

reduction in total phenolic content was significant only for unripe and overripe wines at the highest dose of fibers (dose 2 ), and no effect was observed for dose 1 . The lack of effect of the treatments when fibers were applied to the mature wines points to the influence of the wine phenolic matrix on the effectiveness of fining with fibers from grape pomace, as suggested previously by other authors $[9,10]$. Additionally, it could be asserted that the differences on effectiveness of fining treatments do not seem to be related to wine ethanol contents (Table 1), since ethanol shows a clear trend through maturity, while fining effectiveness do not show those trends. The average reduction in $\mathrm{I}_{280}$ for the unripe wine and overripe wine (dose 2: $2.5 \mathrm{~g} / \mathrm{L}$ ) corresponds to $4.2 \%$ and $3.1 \%$, respectively. Those reductions are lower than those previously reported by Guerrero et al. [10] who found a reduction of around $10 \%$ of the same total phenolic content when fibers from "Cabernet Sauvignon" pomaces were used for wine fining. This difference in fining effectiveness could be related to the treatment conditions. In the present work, the fibers were given at $2.5 \mathrm{~g} / \mathrm{L}$ for 72 hours (stirred once a day), and the solids were removed by simple decantation. Guerrero et al. used a dose of $5.0 \mathrm{~g} / \mathrm{L}$ for 48 hours using a laboratory suspension mixer, and the solids were removed by centrifugation $(2770 \mathrm{~g})$. As reported in the literature, the effectiveness of the treatments strongly depended on the applied dose $[9,10]$, and the higher dose applied, besides the permanent stirring, could explain the larger effect of the fining treatment on $\mathrm{I}_{280}$ reported by Guerrero et al. [10] when compared with our results. After four months of bottle ageing, the effectiveness of the treatment was maintained just for the unripe wines as the unripe wines treated with a high dose of fibers had a statistically lower $\mathrm{I}_{280}$ than the control unripe wine (a reduction of 2.6\%). After nine months of bottle ageing, no statistical differences among the treated wines and their respective controls were observed. Considering the results for $\mathrm{I}_{280}$, it seems that the effectiveness of the treatments on the total phenolic content depends on the initial phenolic composition of the wines and on the applied dose, whereas no trend was observed with the wine alcoholic degree or with the maturity of the grapes used for fiber production, as has been also observed by other authors [10].

The trends observed for grape maturity and bottle ageing for $\mathrm{I}_{280}$ were the same as those observed for total anthocyanin contents (Table 3 ). The grape maturity enhanced the anthocyanin content of the wines, whereas during bottle ageing, the anthocyanin content decreased. Both trends are quite logical and agree with previous studies. The grape maturity enhances the skin anthocyanin content and its extractability from grape skins to wine [27], whereas wine ageing decreases the anthocyanin content. This decrease is due to degradation of monomeric anthocyanins through oxidation and also because of the formation of nonbleachable anthocyanin-derived pigments [30]. Concerning the treatments, no clear effects were observed on total anthocyanin content. As occurred with the total phenolic content, the treatments did not show any effect on the total anthocyanin content with mature wine. Unexpectedly, the fining with grape pomace fibers does not seem to reduce the anthocyanin content of wines as previously reported [10], but on the contrary, it seems to enhance the anthocyanin content of some of the treated wines when compared with the respective untreated control immediately after the treatment. Specifically, the anthocyanin content increases when mature and overripe fibers were applied at dose 1 for unripe wine, when overripe fibers were applied at dose 1 for 
TABle 3: Total anthocyanin content of the wines expressed as $\mathrm{mg} / \mathrm{L}$ of malvidine-O-3-glucoside.

\begin{tabular}{|c|c|c|c|c|c|}
\hline & & & 0 months aged & 4 months aged & 9 months aged \\
\hline \multirow{7}{*}{ Unripe wine } & \multirow{4}{*}{ Dose 1} & Control & $115.6 \pm 10.2 \mathrm{ab} \beta$ & $94.7 \pm 5.3 \mathrm{~b} \alpha$ & $90.3 \pm 4.7 \mathrm{~b} \alpha$ \\
\hline & & Unripe fibers & $125.4 \pm 3.3 \mathrm{bc} \gamma$ & $88.8 \pm 2.4 \mathrm{ab} \beta$ & $82.8 \pm 1.4$ a $\alpha$ \\
\hline & & Mature fibers & $129.2 \pm 0.7$ с $\gamma$ & $92.1 \pm 0.9 \mathrm{ab} \beta$ & $83.9 \pm 1.1$ a $\alpha$ \\
\hline & & Overripe fibers & $131.2 \pm 1.6 \mathrm{c} \gamma$ & $95.1 \pm 1.6 \mathrm{~b} \beta$ & $85.1 \pm 1.2$ a $\alpha$ \\
\hline & \multirow{3}{*}{ Dose 2} & Unripe fibers & $107.9 \pm 5.2$ a $\beta$ & $86.6 \pm 2.8$ a $\alpha$ & $83.5 \pm 1.6$ a $\alpha$ \\
\hline & & Mature fibers & $107.2 \pm 3.2$ a $\gamma$ & $88.8 \pm 1.4 \mathrm{ab} \beta$ & $83.4 \pm 1.1$ a $\alpha$ \\
\hline & & Overripe fibers & $115.7 \pm 5.2 \mathrm{ab} \gamma$ & $91.8 \pm 2.0 \mathrm{ab} \beta$ & $85.0 \pm 0.6$ a $\alpha$ \\
\hline \multirow{7}{*}{ Mature wine } & \multirow{5}{*}{ Dose 1} & Control & $128.5 \pm 7.5$ a $\beta$ & $101.2 \pm 0.8$ a $\alpha$ & $94.2 \pm 2.5 \mathrm{~b} \alpha$ \\
\hline & & Unripe fibers & $134.9 \pm 2.2$ a $\gamma$ & $99.7 \pm 4.0$ a $\beta$ & $83.0 \pm 6.8$ a $\alpha$ \\
\hline & & Mature fibers & $134.9 \pm 2.8$ a $\beta$ & $102.2 \pm 2.7$ a $\alpha$ & $94.5 \pm 2.0 \mathrm{~b} \alpha$ \\
\hline & & Overripe fibers & $136.9 \pm 1.5$ a $\gamma$ & $103.3 \pm 3.2$ a $\beta$ & $93.3 \pm 1.5 \mathrm{~b} \alpha$ \\
\hline & & Unripe fibers & $136.2 \pm 4.2$ a $\gamma$ & $101.7 \pm 1.9$ a $\beta$ & $90.9 \pm 4.2 \mathrm{~b} \alpha$ \\
\hline & \multirow[t]{2}{*}{ Dose 2} & Mature fibers & $138.2 \pm 1.6$ a $\gamma$ & $110.4 \pm 2.2 \mathrm{~b} \beta$ & $96.2 \pm 5.7 \mathrm{~b} \alpha$ \\
\hline & & Overripe fibers & $136.4 \pm 5.6$ a $\beta$ & $105.2 \pm 0.6$ a $\alpha$ & $101.5 \pm 2.3 \mathrm{~b} \alpha$ \\
\hline \multirow{7}{*}{ Overripe wine } & \multirow{5}{*}{ Dose 1} & Control & $135.7 \pm 4.8$ a $\beta$ & $109.0 \pm 0.8$ a $\alpha$ & $103.1 \pm 3.4$ a $\alpha$ \\
\hline & & Unripe fibers & $137.8 \pm 7.5$ ab $\beta$ & $111.8 \pm 4.0$ a $\alpha$ & $101.1 \pm 3.4$ a $\alpha$ \\
\hline & & Mature fibers & $140.4 \pm 2.4 \mathrm{ab} \beta$ & $104.7 \pm 2.7$ a $\alpha$ & $100.0 \pm 3.3$ a $\alpha$ \\
\hline & & Overripe fibers & $152.7 \pm 5.6$ b $\beta$ & $111.3 \pm 3.2$ a $\alpha$ & $101.7 \pm 6.3$ a $\alpha$ \\
\hline & & Unripe fibers & $153.1 \pm 8.4 \mathrm{~b} \beta$ & $107.5 \pm 1.9$ a $\alpha$ & $105.9 \pm 5.9$ a $\alpha$ \\
\hline & \multirow[t]{2}{*}{ Dose 2} & Mature fibers & $152.2 \pm 4.2 \mathrm{~b} \gamma$ & $107.9 \pm 2.2$ a $\beta$ & $101.6 \pm 1.7$ a $\alpha$ \\
\hline & & Overripe fibers & $147.2 \pm 5.4 \mathrm{ab} \gamma$ & $112.1 \pm 0.6$ a $\beta$ & $103.7 \pm 3.9$ a $\alpha$ \\
\hline
\end{tabular}

Note. Different letters in a column show statistical differences $(p<0.05)$ among treatments within each wine class. Different Greek letters in a row indicate statistical differences $(p<0.05)$ among bottle ageing times.

overripe wine, and when unripe and mature fibers were applied at dose 2 for overripe wine. The increase in anthocyanin content could indicate a release of anthocyanins from pomace fibers to wine, which in turn could indicate the presence of anthocyanins on the pomace fibers as impurities. However, during the cell wall material isolation from grape pomaces, over 12 washes with $70 \%$ ethanol $\left(\right.$ at $\left.40^{\circ} \mathrm{C}\right)$ were performed, and no evidence of color release was observed at least in the last three washes. Hence, the release of anthocyanins from pomace fibers to wine is unlikely. On the other hand, the higher amount of total anthocyanins for some of the treated wines could be related to reduced anthocyanin degradation or a lower formation of polymeric pigments and other anthocyanin-derived pigments. The differences in the anthocyanin content of the treated wines declined with bottle ageing because after four months of bottle ageing, just the unripe wine fined with the unripe fibers at dose 2 and the mature wine fined with mature fibers at dose 2 differed from their respective controls. Curiously, after nine months of bottle ageing, all of the treated unripe wines had statistically lower anthocyanin content compared to the untreated unripe wine. These data suggest that the treatments enhanced the reactivity of the anthocyanins throughout the bottle ageing of the wines. In any case, it seems that the fiber treatments did not decrease the anthocyanin content of wines in our conditions. Moreover, no dose effect was observed for the total anthocyanin content of the wines, and no trends were observed for the maturity of grapes used for fiber production.

3.2. Wine Color. In order to know the effect of the treatments on wine color, the color intensity (CI, Table 4), hue ( $T$, Table 5), and CIELab coordinates (Tables 6-8) of the wines were determined. Based on the CI results, once again, it seems that the initial composition of the wines clearly influenced the effectiveness of the treatments, and high doses were required to ensure treatment effects because all of the wines treated at the low dose showed the same CI as the untreated control wines. As occurred with the $\mathrm{I}_{280}$ and the total anthocyanins, the fiber fining had little influence on wine $\mathrm{CI}$ for the mature wines. For unripe wine, the treatments at the high dose $(2.5 \mathrm{~g} / \mathrm{L})$ decreased the CI through four months of bottle ageing. After nine months of bottle ageing, the wines treated at the lowest dose $(0.2 \mathrm{~g} / \mathrm{L})$ showed higher $\mathrm{CI}$ than the control wines, whereas the wines treated with unripe and mature fibers at $2.5 \mathrm{~g} / \mathrm{L}$ (dose 2) showed lower CI. For overripe wine, the CI also decreased when a high dose of fibers was applied, and those differences were maintained throughout the nine months of bottle ageing. These reductions in CI were much lower than those observed by Guerrero et al. [10] who achieved a reduction of around $16 \%$ of CI when fibers from "Cabernet Sauvignon" pomace were added to "Cabernet Sauvignon" wines. However, in this work, treatments were applied under winery-like conditions, whereas Guerrero et al. performed the treatments under laboratory conditions. For the hue ( $T$, Table 5$)$, a clear increasing trend was observed for grape maturity and for wine ageing. The control wines had lower $T$ for all of the wines across ageing, which seems to indicate that wine treatments with cell wall fibers favor the evolution of wine color because the increase in $T$ indicates an increase in the yellow component of wines at the sacrifice of the red ones, which occurs as a result of the formation of anthocyanin-derived pigments and polymeric pigments [30]. For unripe wines, it seems that a dose effect exists almost through four months of ageing because regardless of the fiber used, all of the unripe wines 
TABLE 4: Color intensity (CI) of the wines.

\begin{tabular}{|c|c|c|c|c|c|}
\hline & & & 0 months aged & 4 months aged & 9 months aged \\
\hline \multirow{7}{*}{ Unripe wine } & \multirow{4}{*}{ Dose 1} & Control & $9.64 \pm 0.01 \mathrm{~d} \gamma$ & $8.83 \pm 0.08 c \beta$ & $8.35 \pm 0.06 \mathrm{~b} \alpha$ \\
\hline & & Unripe fibers & $9.56 \pm 0.06 \mathrm{~d} \gamma$ & $8.89 \pm 0.00 \subset \beta$ & $8.45 \pm 0.02$ c $\alpha$ \\
\hline & & Mature fibers & $9.64 \pm 0.09 \mathrm{~d} \gamma$ & $8.88 \pm 0.01$ с $\beta$ & $8.50 \pm 0.11 \mathrm{c} \alpha$ \\
\hline & & Overripe fibers & $9.68 \pm 0.06 \mathrm{~d} \gamma$ & $8.88 \pm 0.03 \subset \beta$ & $8.51 \pm 0.03$ c $\alpha$ \\
\hline & \multirow{3}{*}{ Dose 2} & Unripe fibers & $8.96 \pm 0.05 \mathrm{~b} \gamma$ & $8.53 \pm 0.02$ a $\beta$ & $8.07 \pm 0.05$ a $\alpha$ \\
\hline & & Mature fibers & $8.81 \pm 0.01$ a $\gamma$ & $8.46 \pm 0.05$ a $\beta$ & $8.01 \pm 0.03$ a $\alpha$ \\
\hline & & Overripe fibers & $9.15 \pm 0.05$ с $\gamma$ & $8.73 \pm 0.03 \mathrm{~b} \beta$ & $8.27 \pm 0.03 \mathrm{~b} \alpha$ \\
\hline \multirow{7}{*}{ Mature wine } & \multirow{5}{*}{ Dose 1} & Control & $12.83 \pm 0.10$ bcd $\gamma$ & $11.13 \pm 0.16 \mathrm{ab} \beta$ & $10.68 \pm 0.08$ bc $\alpha$ \\
\hline & & Unripe fibers & $13.05 \pm 0.12 \mathrm{~cd} \gamma$ & $11.24 \pm 0.07 \mathrm{ab} \beta$ & $10.61 \pm 0.12 \mathrm{abc} \alpha$ \\
\hline & & Mature fibers & $13.18 \pm 0.06 \mathrm{~d} \gamma$ & $11.24 \pm 0.03 \mathrm{ab} \beta$ & $10.75 \pm 0.06 \mathrm{c} \alpha$ \\
\hline & & Overripe fibers & $13.10 \pm 0.24 \mathrm{~d} \gamma$ & $11.30 \pm 0.17 \mathrm{~b} \beta$ & $10.91 \pm 0.03 \mathrm{~d} \alpha$ \\
\hline & & Unripe fibers & $12.37 \pm 0.17$ a $\gamma$ & $10.99 \pm 0.09$ a $\beta$ & $10.56 \pm 0.03 \mathrm{ab} \alpha$ \\
\hline & \multirow[t]{2}{*}{ Dose 2} & Mature fibers & $12.51 \pm 0.26 \mathrm{ab} \gamma$ & $11.00 \pm 0.04$ a $\beta$ & $10.60 \pm 0.02 \mathrm{abc} \alpha$ \\
\hline & & Overripe fibers & $12.71 \pm 0.07 \mathrm{abc} \gamma$ & $11.20 \pm 0.03 \mathrm{ab} \beta$ & $10.49 \pm 0.07$ a $\alpha$ \\
\hline \multirow{7}{*}{ Overripe wine } & \multirow{5}{*}{ Dose 1} & Control & $11.93 \pm 0.02$ de $\gamma$ & $11.27 \pm 0.06$ е $\beta$ & $10.61 \pm 0.06 \mathrm{~b} \alpha$ \\
\hline & & Unripe fibers & $11.89 \pm 0.02 \mathrm{~d} \gamma$ & $11.21 \pm 0.04 \mathrm{~d} \beta$ & $10.48 \pm 0.05 \mathrm{~b} \alpha$ \\
\hline & & Mature fibers & $11.94 \pm 0.03$ de $\gamma$ & $10.80 \pm 0.01$ a $\beta$ & $10.55 \pm 0.12 \mathrm{~b} \alpha$ \\
\hline & & Overripe fibers & $11.97 \pm 0.02$ e $\gamma$ & $11.16 \pm 0.01$ с $\beta$ & $10.54 \pm 0.10 \mathrm{~b} \alpha$ \\
\hline & & Unripe fibers & $11.50 \pm 0.03 \mathrm{~b} \gamma$ & $10.80 \pm 0.02$ a $\beta$ & $10.26 \pm 0.07$ a $\alpha$ \\
\hline & \multirow[t]{2}{*}{ Dose 2} & Mature fibers & $11.36 \pm 0.01$ a $\gamma$ & $11.14 \pm 0.02$ с $\beta$ & $10.24 \pm 0.05$ a $\alpha$ \\
\hline & & Overripe fibers & $11.61 \pm 0.05$ c $\gamma$ & $10.90 \pm 0.01 \mathrm{~b} \beta$ & $10.22 \pm 0.07$ a $\alpha$ \\
\hline
\end{tabular}

Note. Different letters in a column show statistical differences $(p<0.05)$ among treatments within each wine class. Different Greek letters in a row indicate statistical differences $(p<0.05)$ among bottle ageing times.

TABLE 5: Hue $(T)$ of the wines.

\begin{tabular}{|c|c|c|c|c|c|}
\hline & & & 0 months aged & 4 months aged & 9 months aged \\
\hline \multirow{7}{*}{ Unripe wine } & \multirow{4}{*}{ Dose 1} & Control & $0.593 \pm 0.002$ a $\alpha$ & $0.602 \pm 0.001$ a $\beta$ & $0.609 \pm 0.003$ a $\gamma$ \\
\hline & & Unripe fibers & $0.593 \pm 0.002$ a $\alpha$ & $0.603 \pm 0.001$ a $\beta$ & $0.613 \pm 0.002 \mathrm{ab} \gamma$ \\
\hline & & Mature fibers & $0.596 \pm 0.004 \mathrm{ab} \alpha$ & $0.605 \pm 0.001$ a $\beta$ & $0.618 \pm 0.004$ с $\gamma$ \\
\hline & & Overripe fibers & $0.594 \pm 0.003$ a $\alpha$ & $0.603 \pm 0.001$ a $\beta$ & $0.616 \pm 0.002$ bc $\gamma$ \\
\hline & \multirow{3}{*}{ Dose 2} & Unripe fibers & $0.599 \pm 0.001 \mathrm{~b} \alpha$ & $0.608 \pm 0.001 \mathrm{~b} \beta$ & $0.612 \pm 0.001 \mathrm{ab} \gamma$ \\
\hline & & Mature fibers & $0.600 \pm 0.001 \mathrm{~b} \alpha$ & $0.610 \pm 0.002 \mathrm{~b} \beta$ & $0.614 \pm 0.001 \mathrm{bc} \gamma$ \\
\hline & & Overripe fibers & $0.600 \pm 0.002 \mathrm{~b} \alpha$ & $0.610 \pm 0.003 \mathrm{~b} \beta$ & $0.615 \pm 0.001 \mathrm{bc} \beta$ \\
\hline \multirow{7}{*}{ Mature wine } & \multirow{5}{*}{ Dose 1} & Control & $0.655 \pm 0.000$ a $\alpha$ & $0.658 \pm 0.001$ a $\beta$ & $0.659 \pm 0.001$ a $\beta$ \\
\hline & & Unripe fibers & $0.656 \pm 0.001 \mathrm{ab} \alpha$ & $0.656 \pm 0.003$ a $\alpha$ & $0.660 \pm 0.001$ a $\alpha$ \\
\hline & & Mature fibers & $0.655 \pm 0.001$ a $\alpha$ & $0.655 \pm 0.003$ a $\alpha$ & $0.663 \pm 0.002 \mathrm{~b} \beta$ \\
\hline & & Overripe fibers & $0.655 \pm 0.001$ a $\alpha$ & $0.656 \pm 0.003$ a $\alpha$ & $0.671 \pm 0.001 \subset \beta$ \\
\hline & & Unripe fibers & $0.656 \pm 0.001 \mathrm{ab} \alpha$ & $0.655 \pm 0.001$ a $\alpha$ & $0.665 \pm 0.003 \mathrm{~b} \beta$ \\
\hline & \multirow[t]{2}{*}{ Dose 2} & Mature fibers & $0.659 \pm 0.001 \subset \beta$ & $0.653 \pm 0.002$ a $\alpha$ & $0.667 \pm 0.001 \mathrm{~b} \gamma$ \\
\hline & & Overripe fibers & $0.658 \pm 0.001$ bc $\alpha$ & $0.657 \pm 0.002$ a $\alpha$ & $0.666 \pm 0.001 \mathrm{~b} \beta$ \\
\hline \multirow{7}{*}{ Overripe wine } & \multirow{4}{*}{ Dose 1} & Control & $0.789 \pm 0.001$ a $\beta$ & $0.790 \pm 0.001$ a $\beta$ & $0.786 \pm 0.001$ a $\alpha$ \\
\hline & & Unripe fibers & $0.789 \pm 0.000$ a $\alpha$ & $0.796 \pm 0.002 \mathrm{ab} \beta$ & $0.793 \pm 0.004$ a $\alpha \beta$ \\
\hline & & Mature fibers & $0.792 \pm 0.000 \mathrm{~b} \alpha$ & $0.798 \pm 0.001 \mathrm{~b} \alpha$ & $0.795 \pm 0.005$ a $\alpha$ \\
\hline & & Overripe fibers & $0.792 \pm 0.001 \mathrm{~b} \alpha$ & $0.792 \pm 0.001$ a $\alpha$ & $0.789 \pm 0.007$ a $\alpha$ \\
\hline & \multirow{3}{*}{ Dose 2} & Unripe fibers & $0.794 \pm 0.000 \mathrm{c} \alpha$ & $0.794 \pm 0.003 \mathrm{ab} \alpha$ & $0.792 \pm 0.008$ a $\alpha$ \\
\hline & & Mature fibers & $0.796 \pm 0.001 \mathrm{~d} \alpha$ & $0.791 \pm 0.002$ a $\alpha$ & $0.793 \pm 0.002$ a $\alpha$ \\
\hline & & Overripe fibers & $0.796 \pm 0.001 \mathrm{~d} \alpha$ & $0.791 \pm 0.003$ a $\alpha$ & $0.793 \pm 0.004$ a $\alpha$ \\
\hline
\end{tabular}

Note. Different letters in a column show statistical differences $(p<0.05)$ among treatments within each wine class. Different Greek letters in a row indicate statistical differences $(p<0.05)$ among bottle ageing times.

treated with dose 2 had higher values of $T$. After nine months of ageing, the dose effect disappeared because wines treated with mature and overripe fibers showed higher values of $T$ for both applied doses. For mature wines, just the wines treated with mature and overripe fibers at dose 2 showed statistically slightly higher values of $T$ just after the treatment, whereas no differences were observed after four months of wine ageing. After nine months of bottle ageing, the control wine and the wine treated with unripe fibers at dose 1 showed lower hue values. For overripe wines, the wines treated with unripe fibers at dose 1 and the control wines showed lower $T$ values just after the treatment, and those differences declined throughout bottle ageing until nine months, when no differences were observed. The slight but statistically significant differences in $T$ between the treated and control wines disagree with the results reported 
TABLE 6: Lightness $\left(L^{*}\right)$ of the wines.

\begin{tabular}{|c|c|c|c|c|c|}
\hline & & & 0 months aged & 4 months aged & 9 months aged \\
\hline \multirow{7}{*}{ Unripe wine } & \multirow{4}{*}{ Dose 1} & Control & $9.63 \pm 0.06$ a $\alpha$ & $11.13 \pm 0.31$ a $\beta$ & $12.50 \pm 0.20 \mathrm{~b} \gamma$ \\
\hline & & Unripe fibers & $9.83 \pm 0.12$ a $\alpha$ & $10.83 \pm 0.06$ a $\beta$ & $12.10 \pm 0.10$ a $\gamma$ \\
\hline & & Mature fibers & $9.43 \pm 0.47$ a $\alpha$ & $10.87 \pm 0.06$ a $\beta$ & $12.10 \pm 0.35$ a $\gamma$ \\
\hline & & Overripe fibers & $9.50 \pm 0.20$ a $\alpha$ & $11.00 \pm 0.17$ a $\beta$ & $12.03 \pm 0.15$ a $\gamma$ \\
\hline & \multirow{3}{*}{ Dose 2} & Unripe fibers & $11.00 \pm 0.17 \mathrm{c} \alpha$ & $11.50 \pm 0.10 \mathrm{~b} \beta$ & $13.20 \pm 0.17$ с $\gamma$ \\
\hline & & Mature fibers & $11.33 \pm 0.06 \mathrm{c} \alpha$ & $11.60 \pm 0.20 \mathrm{~b} \beta$ & $13.40 \pm 0.01 \subset \gamma$ \\
\hline & & Overripe fibers & $10.57 \pm 0.15 \mathrm{~b} \alpha$ & $11.00 \pm 0.10$ a $\beta$ & $12.60 \pm 0.10 \mathrm{~b} \gamma$ \\
\hline \multirow{7}{*}{ Mature wine } & \multirow{4}{*}{ Dose 1} & Control & $5.53 \pm 0.15$ a $\alpha$ & $7.97 \pm 0.35$ a $\beta$ & $9.00 \pm 0.26 \mathrm{~b} \gamma$ \\
\hline & & Unripe fibers & $5.17 \pm 0.15$ a $\alpha$ & $7.70 \pm 0.10$ a $\beta$ & $9.00 \pm 0.26 \mathrm{~b} \gamma$ \\
\hline & & Mature fibers & $5.10 \pm 0.10$ a $\alpha$ & $7.77 \pm 0.12$ a $\beta$ & $8.63 \pm 0.15 \mathrm{ab} \gamma$ \\
\hline & & Overripe fibers & $5.17 \pm 0.32$ a $\alpha$ & $7.63 \pm 0.32$ a $\beta$ & $8.40 \pm 0.10$ a $\gamma$ \\
\hline & \multirow{3}{*}{ Dose 2} & Unripe fibers & $5.93 \pm 0.25$ a $\alpha$ & $8.17 \pm 0.15$ a $\beta$ & $9.07 \pm 0.06 \mathrm{~b} \gamma$ \\
\hline & & Mature fibers & $5.67 \pm 0.40$ a $\alpha$ & $8.03 \pm 0.06$ a $\beta$ & $8.77 \pm 0.06 \mathrm{~b} \gamma$ \\
\hline & & Overripe fibers & $5.53 \pm 0.06$ a $\alpha$ & $7.63 \pm 0.06$ a $\beta$ & $9.03 \pm 0.15 \mathrm{~b} \gamma$ \\
\hline \multirow{7}{*}{ Overripe wine } & \multirow{5}{*}{ Dose 1} & Control & $9.57 \pm 0.06 \mathrm{~b} \alpha$ & $10.83 \pm 0.06$ a $\beta$ & $12.00 \pm 0.17$ a $\gamma$ \\
\hline & & Unripe fibers & $9.60 \pm 0.00 \mathrm{~b} \alpha$ & $11.07 \pm 0.15 \mathrm{~b} \beta$ & $12.43 \pm 0.06 \mathrm{abc} \gamma$ \\
\hline & & Mature fibers & $9.50 \pm 0.10 \mathrm{~b} \alpha$ & $11.13 \pm 0.06 \mathrm{bc} \beta$ & $12.30 \pm 0.26 \mathrm{ab} \gamma$ \\
\hline & & Overripe fibers & $9.33 \pm 0.06$ a $\alpha$ & $11.27 \pm 0.06$ с $\beta$ & $12.23 \pm 0.32 \mathrm{ab} \gamma$ \\
\hline & & Unripe fibers & $10.03 \pm 0.06 \mathrm{~d} \alpha$ & $11.97 \pm 0.06$ e $\beta$ & $12.80 \pm 0.20 \mathrm{bc} \gamma$ \\
\hline & \multirow[t]{2}{*}{ Dose 2} & Mature fibers & $10.37 \pm 0.06$ е $\alpha$ & $11.77 \pm 0.12 \mathrm{~d} \beta$ & $12.70 \pm 0.17 \mathrm{bc} \gamma$ \\
\hline & & Overripe fibers & $9.90 \pm 0.10 \subset \alpha$ & $11.67 \pm 0.06 \mathrm{~d} \beta$ & $12.97 \pm 0.29$ c $\gamma$ \\
\hline
\end{tabular}

Note. Different letters in a column show statistical differences $(p<0.05)$ among treatments within each wine class. Different Greek letters in a row indicate statistical differences $(p<0.05)$ among bottle ageing times.

TABle 7: Redness $\left(a^{*}\right)$ of the wines.

\begin{tabular}{|c|c|c|c|c|c|}
\hline & & & 0 months aged & 4 months aged & 9 months aged \\
\hline \multirow{7}{*}{ Unripe wine } & \multirow{4}{*}{ Dose 1} & Control & $39.75 \pm 0.08$ a $\alpha$ & $41.51 \pm 0.36$ a $\beta$ & $43.06 \pm 0.23 \mathrm{~b} \gamma$ \\
\hline & & Unripe fibers & $40.03 \pm 0.14$ a $\alpha$ & $41.13 \pm 0.07$ a $\beta$ & $42.53 \pm 0.17$ a $\gamma$ \\
\hline & & Mature fibers & $39.52 \pm 0.63$ a $\alpha$ & $41.16 \pm 0.03$ a $\beta$ & $42.47 \pm 0.43$ a $\gamma$ \\
\hline & & Overripe fibers & $39.61 \pm 0.23$ a $\alpha$ & $41.33 \pm 0.21$ a $\beta$ & $42.44 \pm 0.23$ a $\gamma$ \\
\hline & \multirow{3}{*}{ Dose 2} & Unripe fibers & $41.48 \pm 0.21 \mathrm{c} \alpha$ & $41.87 \pm 0.14 \mathrm{~b} \beta$ & $43.76 \pm 0.23 \subset \gamma$ \\
\hline & & Mature fibers & $41.92 \pm 0.10 \mathrm{c} \alpha$ & $41.96 \pm 0.23 \mathrm{~b} \alpha$ & $43.97 \pm 0.04 \subset \beta$ \\
\hline & & Overripe fibers & $40.93 \pm 0.19 \mathrm{~b} \alpha$ & $41.25 \pm 0.13$ a $\beta$ & $43.08 \pm 0.14 \mathrm{~b} \gamma$ \\
\hline \multirow{7}{*}{ Mature wine } & \multirow{5}{*}{ Dose 1} & Control & $32.12 \pm 0.37 \mathrm{ab} \alpha$ & $37.01 \pm 0.43$ a $\beta$ & $38.22 \pm 0.30 \mathrm{~b} \gamma$ \\
\hline & & Unripe fibers & $30.99 \pm 0.62$ a $\alpha$ & $36.67 \pm 0.17$ a $\beta$ & $38.20 \pm 0.31 \mathrm{~b} \gamma$ \\
\hline & & Mature fibers & $30.81 \pm 0.42$ a $\alpha$ & $36.72 \pm 0.18$ a $\beta$ & $37.76 \pm 0.24 \mathrm{ab} \gamma$ \\
\hline & & Overripe fibers & $31.07 \pm 1.01$ a $\alpha$ & $36.54 \pm 0.43$ a $\beta$ & $37.43 \pm 0.11$ a $\beta$ \\
\hline & & Unripe fibers & $33.34 \pm 0.62 \mathrm{~b} \alpha$ & $37.26 \pm 0.16$ a $\beta$ & $38.25 \pm 0.05 \mathrm{~b} \gamma$ \\
\hline & \multirow{2}{*}{ Dose 2} & Mature fibers & $32.55 \pm 1.08 \mathrm{ab} \alpha$ & $37.13 \pm 0.11$ a $\beta$ & $37.88 \pm 0.07 \mathrm{~b} \beta$ \\
\hline & & Overripe fibers & $32.22 \pm 0.17 \mathrm{ab} \alpha$ & $36.61 \pm 0.12$ a $\beta$ & $38.21 \pm 0.13 \mathrm{~b} \gamma$ \\
\hline \multirow{7}{*}{ Overripe wine } & \multirow{5}{*}{ Dose 1} & Control & $38.84 \pm 0.08 \mathrm{~b} \alpha$ & $40.16 \pm 0.07$ a $\beta$ & $41.35 \pm 0.16$ a $\gamma$ \\
\hline & & Unripe fibers & $38.91 \pm 0.03 \mathrm{~b} \alpha$ & $40.38 \pm 0.17 \mathrm{~b} \beta$ & $41.75 \pm 0.04 \mathrm{abc} \gamma$ \\
\hline & & Mature fibers & $38.77 \pm 0.09 \mathrm{~b} \alpha$ & $40.50 \pm 0.05 \mathrm{~b} \beta$ & $41.60 \pm 0.25 \mathrm{ab} \gamma$ \\
\hline & & Overripe fibers & $38.56 \pm 0.03$ a $\alpha$ & $40.70 \pm 0.04$ с $\beta$ & $41.57 \pm 0.26 \mathrm{ab} \gamma$ \\
\hline & & Unripe fibers & $39.34 \pm 0.11 \mathrm{~d} \alpha$ & $41.42 \pm 0.10$ e $\beta$ & $42.18 \pm 0.16 \mathrm{~cd} \gamma$ \\
\hline & \multirow[t]{2}{*}{ Dose 2} & Mature fibers & $39.78 \pm 0.07$ e $\alpha$ & $41.22 \pm 0.10 \mathrm{~d} \beta$ & $42.03 \pm 0.14 \mathrm{bcd} \gamma$ \\
\hline & & Overripe fibers & $39.17 \pm 0.16$ c $\alpha$ & $41.17 \pm 0.03 \mathrm{~d} \beta$ & $42.40 \pm 0.31 \mathrm{~d} \gamma$ \\
\hline
\end{tabular}

Note. Different letters in a column show statistical differences $(p<0.05)$ among treatments within each wine class. Different Greek letters in a row indicate statistical differences $(p<0.05)$ among bottle ageing times.

by Guerrero et al. [10] who did not find differences in wine hue when fibers from "Cabernet Sauvignon" grape pomace were applied to "Cabernet Sauvignon" wines under laboratory conditions.

For a better understanding of wine color changes due to treatment, the CIELab coordinates were also determined. Lightness $\left(L^{*}\right.$, Table 6$)$ indicates the luminosity of the wines. This parameter ranges from 0 (fully opaque) to 100 (fully transparent); hence, the lower the $L^{*}$, the deeper is the wine color. Redness $\left(a^{*}\right.$, Table 7$)$ indicates the intensity of red color for positive values (and the intensity of green color for negative values), and the higher the $a^{*}$, the higher is the red component of the wines. Yellowness $\left(b^{*}\right.$, Table 8$)$ indicates the intensity of yellow color for positive values (and the intensity of blue color for negative values), and the higher the $b^{*}$, the higher is the yellow component of the wines. 
TABLE 8: Yellowness $\left(b^{*}\right)$ of the wines.

\begin{tabular}{|c|c|c|c|c|c|}
\hline & & & 0 months aged & 4 months aged & 9 months aged \\
\hline \multirow{7}{*}{ Unripe wine } & \multirow{4}{*}{ Dose 1} & Control & $16.05 \pm 0.09 \mathrm{ab} \alpha$ & $18.27 \pm 0.43$ a $\beta$ & $20.27 \pm 0.24 \mathrm{ab} \gamma$ \\
\hline & & Unripe fibers & $16.38 \pm 0.16 \mathrm{~b} \alpha$ & $17.80 \pm 0.09$ a $\beta$ & $19.71 \pm 0.22$ a $\gamma$ \\
\hline & & Mature fibers & $15.79 \pm 0.74$ a $\alpha$ & $17.85 \pm 0.04$ a $\beta$ & $19.73 \pm 0.49$ a $\gamma$ \\
\hline & & Overripe fibers & $15.88 \pm 0.28 \mathrm{ab} \alpha$ & $18.05 \pm 0.24$ a $\beta$ & $19.68 \pm 0.26$ a $\gamma$ \\
\hline & \multirow{3}{*}{ Dose 2} & Unripe fibers & $18.10 \pm 0.25 \mathrm{~d} \alpha$ & $18.68 \pm 0.15 \mathrm{~b} \beta$ & $21.16 \pm 0.24$ с $\gamma$ \\
\hline & & Mature fibers & $18.59 \pm 0.12 \mathrm{~d} \alpha$ & $18.78 \pm 0.24 \mathrm{~b} \alpha$ & $21.44 \pm 0.05$ с $\beta$ \\
\hline & & Overripe fibers & $17.44 \pm 0.23$ c $\alpha$ & $17.98 \pm 0.12$ a $\beta$ & $20.43 \pm 0.14 \mathrm{~b} \gamma$ \\
\hline \multirow{7}{*}{ Mature wine } & \multirow{4}{*}{ Dose 1} & Control & $9.48 \pm 0.22 \mathrm{ab} \alpha$ & $13.65 \pm 0.55 \mathrm{ab} \beta$ & $15.34 \pm 0.41 \mathrm{~b} \gamma$ \\
\hline & & Unripe fibers & $8.87 \pm 0.31$ a $\alpha$ & $13.18 \pm 0.20 \mathrm{ab} \beta$ & $15.33 \pm 0.42 \mathrm{~b} \gamma$ \\
\hline & & Mature fibers & $8.77 \pm 0.21$ a $\alpha$ & $13.25 \pm 0.23 \mathrm{ab} \beta$ & $14.77 \pm 0.30 \mathrm{ab} \gamma$ \\
\hline & & Overripe fibers & $8.92 \pm 0.51$ a $\alpha$ & $13.05 \pm 0.50$ a $\beta$ & $14.36 \pm 0.13$ a $\gamma$ \\
\hline & \multirow{3}{*}{ Dose 2} & Unripe fibers & $10.24 \pm 0.41 \mathrm{~b} \alpha$ & $13.95 \pm 0.21 \mathrm{~b} \beta$ & $15.45 \pm 0.09 \mathrm{~b} \gamma$ \\
\hline & & Mature fibers & $9.77 \pm 0.66 \mathrm{ab} \alpha$ & $13.76 \pm 0.14 \mathrm{ab} \beta$ & $14.98 \pm 0.10 \mathrm{~b} \gamma$ \\
\hline & & Overripe fibers & $9.54 \pm 0.10 \mathrm{ab} \alpha$ & $13.11 \pm 0.13 \mathrm{ab} \beta$ & $15.43 \pm 0.18 \mathrm{~b} \gamma$ \\
\hline \multirow{7}{*}{ Overripe wine } & \multirow{4}{*}{ Dose 1} & Control & $16.47 \pm 0.10 \mathrm{~b} \alpha$ & $18.64 \pm 0.10$ a $\beta$ & $20.64 \pm 0.27$ a $\gamma$ \\
\hline & & Unripe fibers & $16.57 \pm 0.02 \mathrm{~b} \alpha$ & $19.04 \pm 0.25 \mathrm{~b} \beta$ & $21.40 \pm 0.02$ abcd $\gamma$ \\
\hline & & Mature fibers & $16.39 \pm 0.13$ b $\alpha$ & $19.14 \pm 0.09$ b $\beta$ & $21.11 \pm 0.48$ abc $\gamma$ \\
\hline & & Overripe fibers & $16.11 \pm 0.04$ a $\alpha$ & $19.41 \pm 0.09$ с $\beta$ & $21.02 \pm 0.49 \mathrm{ab} \gamma$ \\
\hline & \multirow{3}{*}{ Dose 2} & Unripe fibers & $17.30 \pm 0.12 \mathrm{~d} \alpha$ & $20.57 \pm 0.15$ e $\beta$ & $22.01 \pm 0.38 \mathrm{~cd} \gamma$ \\
\hline & & Mature fibers & $17.91 \pm 0.10$ e $\alpha$ & $20.26 \pm 0.18 \mathrm{~d} \beta$ & $21.83 \pm 0.25 \mathrm{bcd} \gamma$ \\
\hline & & Overripe fibers & $17.04 \pm 0.21$ с $\alpha$ & $20.07 \pm 0.07 \mathrm{~d} \beta$ & $22.29 \pm 0.51 \mathrm{~d} \gamma$ \\
\hline
\end{tabular}

Note. Different letters in a column show statistical differences $(p<0.05)$ among treatments within each wine class. Different Greek letters in a row indicate statistical differences $(p<0.05)$ among bottle ageing times.

Considering the results for the CIELab coordinates, wine color clearly decreased throughout bottle ageing, which could be observed by the decrease in $L^{*}$. Moreover, yellow and red components increased during bottle ageing, whereas the blue component decreased, which could be observed by the increase in $b^{*}$ and $a^{*}$, respectively. Concerning the treatment, once again, the treatments had minimal impact on the mature wine because the treated wines did not show statistically significant differences when compared with the controls. For unripe wine, there appeared to be a dose effect because regardless of the fiber applied, the wines treated at dose 2 had higher $L^{*}, a^{*}$, and $b^{*}$ than the control unripe wine just after the treatment ( 0 months ageing). After four months of ageing, the effect of the overripe fiber at dose 2 disappeared, whereas the wines treated with unripe and mature fibers had higher values of $L^{*}, a^{*}$, and $b^{*}$. Therefore, the treated unripe wines had less color density, higher red and yellow components, and a lower blue component when compared with the control unripe wine. After nine months of bottle ageing, the wines treated with dose 1 showed lower values of $L^{*}$ and $a^{*}$, which indicated that these wines had deeper color and a lower red component. Moreover, these wines also showed lower values of $b^{*}$ (despite these values not being statistically different from control wines), which indicated a lower yellow contribution. These data agree with the aforementioned results of $\mathrm{CI}$ and $\mathrm{T}$ for the same wines, which could indicate that the applied treatments at dose 1 delayed the evolution of color for unripe wines after several months of bottle ageing. For overripe wine, the treatments applied at dose 1 only showed higher values of $L^{*}, a^{*}$, and $b^{*}$ compared to overripe control wine after four months of bottle ageing. When the treatments were applied at dose 2 , the values of $L^{*}, a^{*}$, and $b^{*}$ of the treated wines were greater than those of control overripe wines, regardless of the fiber applied and the bottle ageing time. Taking into account all of the color data (traditional parameters and CIELab coordinates), it seems that treatment of wines with grape pomace fibers has a slight but statistically significant effect on wine color depending on the initial features of the treated wine, as also occurs with the $I_{280}$ and the total anthocyanin content.

3.3. Wine Proanthocyanidins. The proanthocyanidin analysis was performed by phloroglucinolysis. As shown in Table 9, the proanthocyanidin content of wine increased with grape maturity, especially between unripe and mature wines. Moreover, this proanthocyanidin content decreased throughout bottle ageing. It seems that treatment had no effect on the proanthocyanidin content because no differences were observed between control wines and their respective treated wines, and no clear trends were observed among doses or the maturity of the grapes used for fiber production. Considering the slight but statistically significant differences observed on $\mathrm{I}_{280}$, the lack of differences in the proanthocyanidin content among treatments is surprising. Despite the fact that phloroglucinolysis has been described as an effective method to observe the decrease in tannin content when model solutions of commercial tannins or purified grape tannins are used to study the interactions between tannins and cell wall material $[1,8,9,14]$, it has also been described that cell walls have high affinity for some oxidized tannins that were not depolymerized by phloroglucinolysis $[1,8,9,13,14]$. Moreover, some interflavanic bonds between anthocyanins and proanthocyanidins are not hydrolyzed by the phloroglucinolysis reagent [31], and their respective adducts are not quantified by our chromatographic method. Therefore, if these polymeric pigmented 
TABLe 9: Proanthocyanidin content of the wines expressed as $\mathrm{mg} / \mathrm{L}$.

\begin{tabular}{|c|c|c|c|c|c|}
\hline & & & 0 months aged & 4 months aged & 9 months aged \\
\hline \multirow{7}{*}{ Unripe wine } & \multirow{4}{*}{ Dose 1} & Control & $515 \pm 34$ a $\alpha$ & $521 \pm 61$ a $\alpha$ & $605 \pm 22$ a $\alpha$ \\
\hline & & Unripe fibers & $499 \pm 20$ a $\alpha$ & $552 \pm 2$ a $\alpha$ & $540 \pm 63$ a $\alpha$ \\
\hline & & Mature fibers & $518 \pm 8$ a $\alpha$ & $556 \pm 68$ a $\alpha$ & $627 \pm 34$ a $\alpha$ \\
\hline & & Overripe fibers & $531 \pm 17$ a $\beta$ & $535 \pm 13$ a $\beta$ & $495 \pm 14$ a $\alpha$ \\
\hline & \multirow{3}{*}{ Dose 2} & Unripe fibers & $570 \pm 51$ a $\beta$ & $455 \pm 17$ a $\alpha$ & $504 \pm 32$ a $\alpha \beta$ \\
\hline & & Mature fibers & $544 \pm 26$ a $\alpha$ & $524 \pm 25$ a $\alpha$ & $496 \pm 16$ a $\alpha$ \\
\hline & & Overripe fibers & $600 \pm 87$ a $\alpha$ & $507 \pm 17$ a $\alpha$ & $573 \pm 14$ a $\alpha$ \\
\hline \multirow{7}{*}{ Mature wine } & \multirow{5}{*}{ Dose 1} & Control & $637 \pm 48$ a $\alpha$ & $559 \pm 56$ a $\alpha$ & $527 \pm 54 \mathrm{ab} \alpha$ \\
\hline & & Unripe fibers & $642 \pm 26$ a $\beta$ & $544 \pm 3$ a $\alpha$ & $505 \pm 6$ a $\alpha$ \\
\hline & & Mature fibers & $644 \pm 15$ a $\beta$ & $770 \pm 2 \mathrm{~b} \gamma$ & $524 \pm 18 \mathrm{ab} \alpha$ \\
\hline & & Overripe fibers & $631 \pm 74$ a $\beta$ & $667 \pm 21 \mathrm{ab} \beta$ & $494 \pm 13$ a $\alpha$ \\
\hline & & Unripe fibers & $732 \pm 87$ a $\alpha$ & $603 \pm 18$ a $\alpha$ & $594 \pm 44 \mathrm{~b} \alpha$ \\
\hline & \multirow[t]{2}{*}{ Dose 2} & Mature fibers & $677 \pm 66$ a $\beta$ & $594 \pm 4$ a $\alpha \beta$ & $531 \pm 29 \mathrm{ab} \alpha$ \\
\hline & & Overripe fibers & $694 \pm 17$ a $\gamma$ & $599 \pm 3$ a $\beta$ & $547 \pm 14 \mathrm{ab} \alpha$ \\
\hline \multirow{7}{*}{ Overripe wine } & \multirow{4}{*}{ Dose 1} & Control & $675 \pm 14 \mathrm{ab} \alpha$ & $670 \pm 51$ a $\alpha$ & $586 \pm 4$ b $\alpha$ \\
\hline & & Unripe fibers & $701 \pm 62 \mathrm{ab} \beta$ & $658 \pm 59$ a $\alpha \beta$ & $570 \pm 24 \mathrm{~b} \alpha$ \\
\hline & & Mature fibers & $606 \pm 71$ a $\alpha$ & $562 \pm 4$ a $\alpha$ & $613 \pm 32 \mathrm{~b} \alpha$ \\
\hline & & Overripe fibers & $667 \pm 27 \mathrm{ab} \alpha$ & $659 \pm 26$ a $\alpha$ & $625 \pm 5 \mathrm{~b} \alpha$ \\
\hline & \multirow{3}{*}{ Dose 2} & Unripe fibers & $768 \pm 20 \mathrm{bc} \beta$ & $698 \pm 76$ a $\beta$ & $419 \pm 21$ a $\alpha$ \\
\hline & & Mature fibers & $827 \pm 27$ с $\gamma$ & $720 \pm 28$ a $\beta$ & $416 \pm 7$ a $\alpha$ \\
\hline & & Overripe fibers & $761 \pm 51$ bc $\gamma$ & $563 \pm 68$ a $\beta$ & $426 \pm 40$ a $\alpha$ \\
\hline
\end{tabular}

Note. Different letters in a column show statistical differences $(p<0.05)$ among treatments within each wine class. Different Greek letters in a row indicate statistical differences $(p<0.05)$ among bottle ageing times.

compounds interact with grape pomace fibers as previously reported by other authors [10], they could also partially explain the slight but statistically significant differences in wine color parameters and the lack of differences in proanthocyanidin content after treatment under our conditions. A competition for the adsorption sites of cell wall fibers between anthocyanins and tannins has been described when model solutions were used for tannin-cell wall interaction studies [13]. Additionally, Guerrero et al. [10] reported a decrease in flavan-3-ols, flavonols, nonbleachable pigments, and polymeric pigments when grape pomace fibers were used for red wine fining. Therefore, it is possible that other phenolic compounds of wine compete together with the anthocyanins for the adsorption sites of the cell wall material, decreasing the amount of proanthocyanidins removed by the treatment, which could also explain the decrease in $\mathrm{I}_{280}$ and the lack of differences in proanthocyanidin content. Despite the fact that no differences in proanthocyanidin content were observed in general terms among treated wines, it should be noted that the overripe wines treated with dose 2 show statistically lower proanthocyanidin content than the control wine and the wine treated with dose 1 overripe wines after nine months of bottle ageing. These data seem to indicate that the fining treatment of wines with grape pomace fibers could affect the phenolic evolution of the wines after several months of ageing, but it depends on the initial wine matrix.

The mDP of proanthocyanidins (Table 10) decreased from unripe wine to mature wine and also decreased throughout bottle ageing through nine months for all of the wines. Concerning the applied treatments, no statistical trends were observed for mDP. Despite the fact that the literature points to the high affinity between high-molecularmass tannins and cell wall fibers $[1,9,14]$, no clear behavior for the $\mathrm{mDP}$ of purified proanthocyanidins (determined by phloroglucinolysis) after treatment with cell wall fibers was found. Previous work described slight differences in $\mathrm{mDP}$, which could increase or decrease depending on the tannin composition $[1,8,13,14]$, on the cultivar used for cell wall fiber extraction $[9,14]$, and on the presence or absence of anthocyanins [13]. Hence, if no changes were observed in proanthocyanidin $\mathrm{mDP}$ when purified tannins in synthetic solutions were used under laboratory conditions to study their interaction with cell wall fibers, it is not surprising that there was a lack of differences in proanthocyanidin $\mathrm{mDP}$ after wine treatments in our study.

3.4. Polysaccharides. When proteinaceous agents were used for wine fining, some protein may remain in the solution, which is a phenomenon known as overfining [11]. In the case of the use of grape cell wall fibers for wine fining, there is no risk of protein overfining because of its carbohydrate nature. However, the possibility that pomace fibers release some polysaccharides to the wine needs to be considered, as this fact could determine the fiber classification as wine adjuvant or wine additive. For that reason, in the present work, the polysaccharides of the wines were quantified (Table 11). In general terms, the wine polysaccharides increased with grape maturity, as previously reported [27]. Moreover, the polysaccharide content of wines seemed to decrease between four and nine months of bottle ageing. These data disagree with previous studies that suggest that wine polysaccharides are globally stable for several years after wine production $[32,33]$. Concerning the treatments, no statistical trend in polysaccharide content was observed among the applied doses or the maturity of the grapes used for fiber extraction. 
TABLE 10: Mean degree of polymerization (mDP) of the wine proanthocyanidins.

\begin{tabular}{|c|c|c|c|c|c|}
\hline & & & 0 months aged & 4 months aged & 9 months aged \\
\hline \multirow{7}{*}{ Unripe wine } & \multirow{4}{*}{ Dose 1} & Control & $5.22 \pm 0.08$ a $\beta$ & $5.28 \pm 0.28$ a $\beta$ & $4.30 \pm 0.14$ a $\alpha$ \\
\hline & & Unripe fibers & $4.94 \pm 0.48$ a $\alpha \beta$ & $5.66 \pm 0.05$ a $\beta$ & $3.88 \pm 0.79$ a $\alpha$ \\
\hline & & Mature fibers & $5.01 \pm 0.55$ a $\beta$ & $5.60 \pm 0.36$ a $\beta$ & $3.40 \pm 0.56$ a $\alpha$ \\
\hline & & Overripe fibers & $5.35 \pm 0.01$ a $\beta$ & $5.68 \pm 0.15$ a $\gamma$ & $4.70 \pm 0.06$ a $\alpha$ \\
\hline & \multirow{3}{*}{ Dose 2} & Unripe fibers & $5.32 \pm 0.13$ a $\beta$ & $5.53 \pm 0.13$ a $\beta$ & $4.65 \pm 0.35$ a $\alpha$ \\
\hline & & Mature fibers & $5.14 \pm 0.07$ a $\beta$ & $5.63 \pm 0.12$ a $\gamma$ & $4.71 \pm 0.33$ a $\alpha$ \\
\hline & & Overripe fibers & $5.23 \pm 0.08$ a $\alpha$ & $5.56 \pm 0.07$ a $\alpha$ & $5.46 \pm 0.23$ a $\alpha$ \\
\hline \multirow{7}{*}{ Mature wine } & \multirow{5}{*}{ Dose 1} & Control & $5.09 \pm 0.11 \mathrm{ab} \beta$ & $4.57 \pm 0.10$ a $\alpha$ & $4.14 \pm 0.35$ a $\alpha$ \\
\hline & & Unripe fibers & $5.17 \pm 0.16 \mathrm{ab} \beta$ & $4.59 \pm 0.04$ a $\alpha$ & $4.49 \pm 0.10$ a $\alpha$ \\
\hline & & Mature fibers & $5.19 \pm 0.07 \mathrm{ab} \gamma$ & $4.23 \pm 0.24$ a $\beta$ & $3.36 \pm 0.66$ a $\alpha$ \\
\hline & & Overripe fibers & $5.16 \pm 0.15 \mathrm{ab} \alpha$ & $4.29 \pm 0.24$ a $\alpha$ & $4.77 \pm 0.78$ a $\alpha$ \\
\hline & & Unripe fibers & $5.33 \pm 0.24 \mathrm{~b} \alpha$ & $4.59 \pm 0.65$ a $\alpha$ & $4.53 \pm 0.24$ a $\alpha$ \\
\hline & \multirow[t]{2}{*}{ Dose 2} & Mature fibers & $4.88 \pm 0.03$ a $\alpha$ & $4.71 \pm 0.36$ a $\alpha$ & $4.66 \pm 0.40$ a $\alpha$ \\
\hline & & Overripe fibers & $5.06 \pm 0.15 \mathrm{ab} \alpha$ & $4.72 \pm 0.25$ a $\alpha$ & $5.01 \pm 0.27$ a $\alpha$ \\
\hline \multirow{7}{*}{ Overripe wine } & \multirow{4}{*}{ Dose 1} & Control & $4.70 \pm 0.14$ a $\alpha$ & $4.57 \pm 0.13$ a $\alpha$ & $4.39 \pm 0.24$ a $\alpha$ \\
\hline & & Unripe fibers & $4.94 \pm 0.14$ a $\beta$ & $4.75 \pm 0.13 \mathrm{ab} \alpha \beta$ & $4.41 \pm 0.28$ a $\alpha$ \\
\hline & & Mature fibers & $4.89 \pm 0.15$ a $\beta$ & $4.77 \pm 0.01 \mathrm{ab} \beta$ & $4.32 \pm 0.01$ a $\alpha$ \\
\hline & & Overripe fibers & $4.68 \pm 0.02$ a $\alpha$ & $5.11 \pm 0.16 \mathrm{~b} \alpha$ & $5.10 \pm 0.22$ a $\alpha$ \\
\hline & \multirow{3}{*}{ Dose 2} & Unripe fibers & $5.01 \pm 0.14$ a $\beta$ & $3.99 \pm 0.11$ a $\alpha$ & $5.14 \pm 0.52$ a $\beta$ \\
\hline & & Mature fibers & $5.06 \pm 0.07$ a $\beta$ & $4.10 \pm 0.09$ a $\alpha$ & $5.23 \pm 0.18$ a $\beta$ \\
\hline & & Overripe fibers & $4.91 \pm 0.24$ a $\beta$ & $4.06 \pm 0.15$ a $\alpha$ & $4.33 \pm 0.09$ a $\alpha$ \\
\hline
\end{tabular}

Note. Different letters in a column show statistical differences $(p<0.05)$ among treatments within each wine class. Different Greek letters in a row indicate statistical differences $(p<0.05)$ among bottle ageing times.

TABLE 11: Total polysaccharide content of the wines expressed as $\mathrm{mg} / \mathrm{L}$.

\begin{tabular}{|c|c|c|c|c|c|}
\hline & & & 0 months aged & 4 months aged & 9 months aged \\
\hline \multirow{7}{*}{ Unripe wine } & \multirow{4}{*}{ Dose 1} & Control & $515 \pm 49 \mathrm{ab} \alpha$ & $652 \pm 35$ a $\alpha$ & $621 \pm 23$ a $\alpha$ \\
\hline & & Unripe fibers & $445 \pm 87$ a $\alpha$ & $633 \pm 76$ a $\alpha$ & $534 \pm 68$ a $\alpha$ \\
\hline & & Mature fibers & $582 \pm 19$ abc $\alpha$ & $637 \pm 89$ a $\alpha$ & $558 \pm 1$ a $\alpha$ \\
\hline & & Overripe fibers & $626 \pm 51$ bc $\alpha$ & $585 \pm 32$ a $\alpha$ & $571 \pm 8$ a $\alpha$ \\
\hline & \multirow{3}{*}{ Dose 2} & Unripe fibers & $460 \pm 66 \mathrm{ab} \beta$ & $705 \pm 40$ a $\alpha$ & $479 \pm 7$ a $\alpha$ \\
\hline & & Mature fibers & $620 \pm 62 \mathrm{bc} \alpha$ & $543 \pm 62$ a $\alpha$ & $402 \pm 44$ a $\alpha$ \\
\hline & & Overripe fibers & $721 \pm 6 c \alpha$ & $619 \pm 59$ a $\alpha$ & $582 \pm 56$ a $\alpha$ \\
\hline \multirow{7}{*}{ Mature wine } & \multirow{5}{*}{ Dose 1} & Control & $838 \pm 90$ a $\beta$ & $854 \pm 26$ a $\beta$ & $679 \pm 31$ a $\alpha$ \\
\hline & & Unripe fibers & $828 \pm 32$ a $\beta$ & $871 \pm 17$ a $\beta$ & $675 \pm 70$ a $\alpha$ \\
\hline & & Mature fibers & $795 \pm 67$ a $\beta$ & $947 \pm 20$ b $\alpha$ & $705 \pm 56$ a $\alpha$ \\
\hline & & Overripe fibers & $819 \pm 24$ a $\gamma$ & $941 \pm 10 \mathrm{~b} \beta$ & $686 \pm 39$ a $\alpha$ \\
\hline & & Unripe fibers & $774 \pm 38$ a $\beta$ & $835 \pm 54$ a $\alpha \beta$ & $695 \pm 60$ a $\alpha$ \\
\hline & \multirow[t]{2}{*}{ Dose 2} & Mature fibers & $798 \pm 111$ a $\beta$ & $885 \pm 13$ ab $\alpha \beta$ & $712 \pm 41$ a $\alpha$ \\
\hline & & Overripe fibers & $879 \pm 42$ a $\gamma$ & $951 \pm 29 \mathrm{~b} \beta$ & $649 \pm 8$ a $\alpha$ \\
\hline \multirow{7}{*}{ Overripe wine } & \multirow{4}{*}{ Dose 1} & Control & $860 \pm 36$ a $\beta$ & $881 \pm 22 \mathrm{ab} \beta$ & $719 \pm 28$ a $\alpha$ \\
\hline & & Unripe fibers & $940 \pm 54 \mathrm{ab} \alpha$ & $870 \pm 9$ a $\alpha$ & $736 \pm 52$ a $\alpha$ \\
\hline & & Mature fibers & $955 \pm 18 \mathrm{ab} \beta$ & $927 \pm 42 \mathrm{abc} \beta$ & $729 \pm 74$ a $\alpha$ \\
\hline & & Overripe fibers & $938 \pm 71$ ab $\beta$ & $917 \pm 41 \mathrm{abc} \beta$ & $675 \pm 19$ a $\alpha$ \\
\hline & \multirow{3}{*}{ Dose 2} & Unripe fibers & $1015 \pm 16$ b $\gamma$ & $956 \pm 28$ с $\beta$ & $724 \pm 68$ a $\alpha$ \\
\hline & & Mature fibers & $851 \pm 88$ a $\alpha$ & $946 \pm 19$ bc $\alpha$ & $818 \pm 36$ a $\alpha$ \\
\hline & & Overripe fibers & $875 \pm 19 \mathrm{ab} \beta$ & $894 \pm 8$ abc $\beta$ & $740 \pm 19$ a $\alpha$ \\
\hline
\end{tabular}

Note. Different letters in a column show statistical differences $(p<0.05)$ among treatments within each wine class. Different Greek letters in a row indicate statistical differences $(p<0.05)$ among bottle ageing times.

Therefore, in view of the obtained results, it seems that the pomace fibers used in our study do not release polysaccharides into the wine.

3.5. Principal Component Analysis. Because larger differences between the treated wines and their respective untreated controls were observed by spectrophotometric measurements, all of the obtained spectrophotometric data were used to perform a multivariate statistical analysis (principal component analysis, PCA) in order to reduce the number of variables and achieve a better understanding of all the results. The wine scores for PCA are shown in Figure 1, and the contributions of each variable to the principal components are shown in Table 12. The first component (PC 1) explained $48.93 \%$ of the variance, and the 


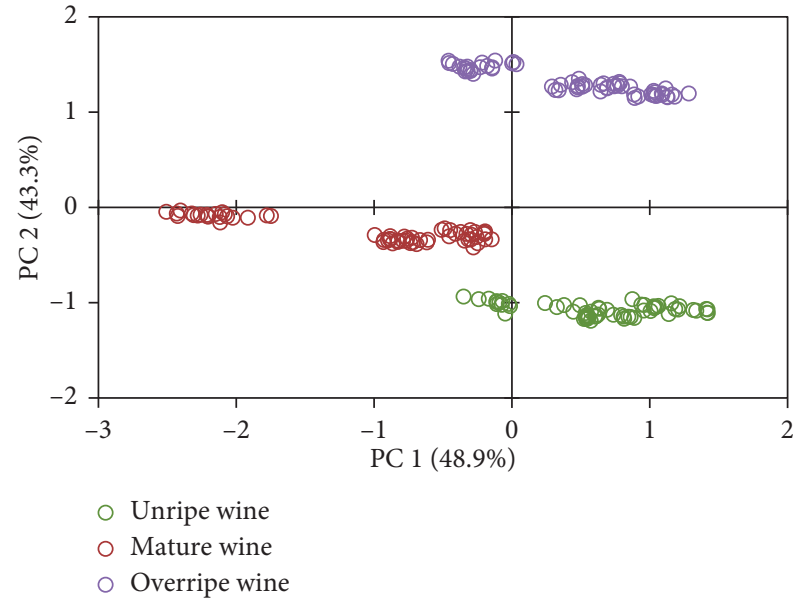

(a)

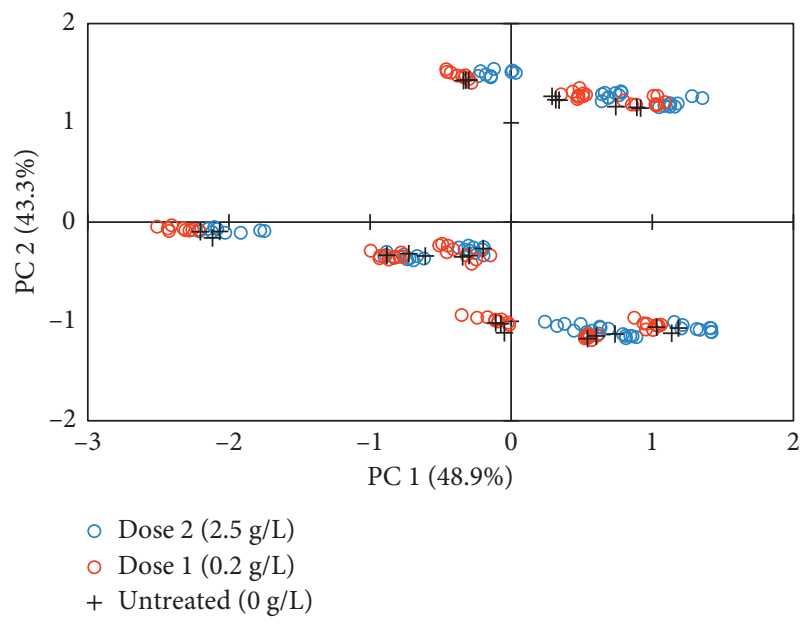

(c)

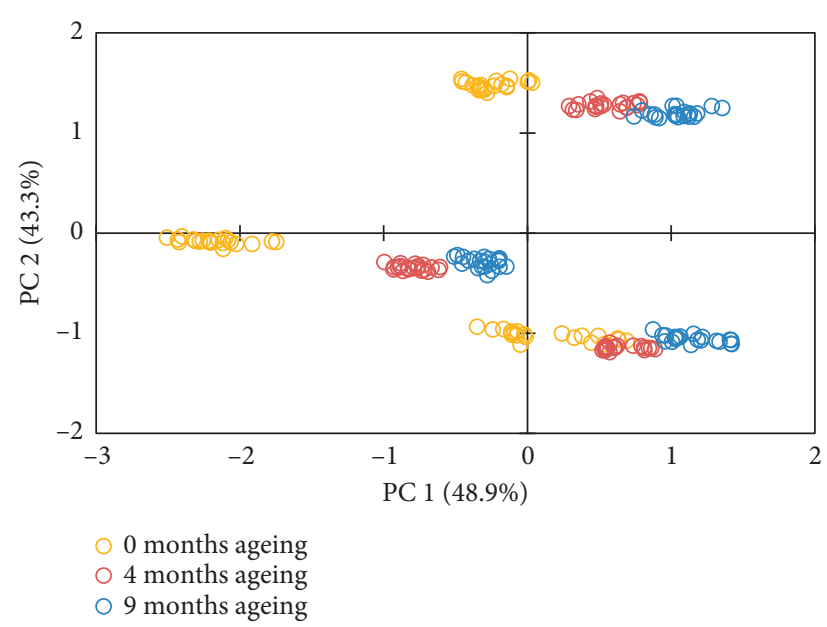

(b)

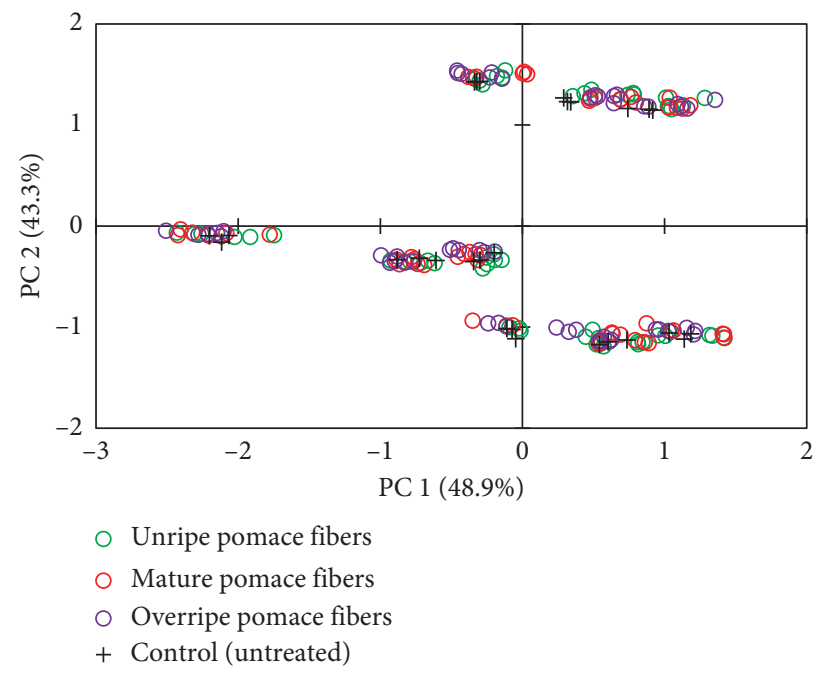

(d)

FIGURE 1: Principal component analysis (PCA) scores for the analyzed wines. Markers depicted as a function of the maturity of the grapes used for winemaking (a), the bottle ageing time (b), the dose of fibers applied (c), and the maturity of the grapes used to obtain the fibers from grape pomace (d).

second component (PC 2) explained $43.31 \%$ of the variance. The cumulative variance explained by both components reached $92.24 \%$. The PCA scores showed that the main differences among wine samples were related to the maturity of the grapes used for winemaking (as can be observed in Figure 1(a)) and also to the bottle ageing time (as can be observed in Figure 1(b)). According to the obtained scores for all of the analyzed wines, it seems that PC 1 was related to the ageing of the wines: the more aged the wines, the higher the PC 1 values. Thus, the ageing of the wines moved the points towards the right side of the graph. In contrast, PC 2 was related to the maturity of the grapes used for winemaking: the wines from riper grapes showed higher PC 2 values. It is very interesting to see what happens when the values are depicted as a function of the applied dose of fibers (Figure 1(c)). Excluding the samples corresponding to the mature wines after four and nine months of ageing, it seems that, for each wine at each ageing time, the wines treated with the high dose of fibers (dose 2) had higher PC 1 scores. Therefore, the results suggest that treatment with high doses of fibers could accelerate wine evolution when compared with the control wines. In contrast, the use of low doses of fibers seems to delay wine evolution when compared with the untreated control samples immediately after the treatment of the three wines, as well as after four and nine months of bottle ageing for unripe wines. Finally, no grouping of scores was observed when they are depicted as a function of the maturity of the grapes employed to produce the fibers (Figure 1(d)). Thus, the results seem to indicate that the maturity of the grapes from which the fibers came did not influence the effectiveness of the treatments.

\section{Conclusions}

Based on the overall results obtained from this study, it seems that larger effects of treatment were observed for unripe and overripe wines, whereas the effect of the 
TABle 12: Contribution of the variables to each principal component for the analyzed wines.

\begin{tabular}{|c|c|c|}
\hline Variable & PC 1 & PC 2 \\
\hline$C^{*}$ & 0.995 & 0.033 \\
\hline$L^{*}$ & 0.991 & 0.081 \\
\hline$a^{*}$ & 0.989 & -0.043 \\
\hline$b^{*}$ & 0.980 & 0.184 \\
\hline$a^{*} / b^{*}$ ratio & -0.963 & -0.227 \\
\hline$b^{*} / C^{*}$ ratio & 0.959 & 0.278 \\
\hline$h^{*}$ & 0.958 & 0.282 \\
\hline$a^{*} / C^{*}$ ratio & -0.932 & -0.326 \\
\hline $\mathrm{CI}$ & -0.794 & 0.601 \\
\hline Intensity $^{\mathrm{a}}$ & -0.747 & 0.659 \\
\hline Hue & 0.129 & 0.989 \\
\hline Yellow (\%) & 0.123 & 0.989 \\
\hline Red (\%) & -0.109 & -0.987 \\
\hline $\mathrm{dA}(\%)^{\mathrm{b}}$ & -0.118 & -0.987 \\
\hline Tone $^{\mathrm{a}}$ & 0.177 & 0.983 \\
\hline Blue (\%) & -0.133 & -0.982 \\
\hline $\mathrm{I}_{280}$ & -0.335 & 0.930 \\
\hline $\mathrm{K}-\mathrm{K}^{\mathrm{c}}$ & -0.692 & 0.710 \\
\hline Chemical age $^{\mathrm{d}}$ & 0.140 & -0.254 \\
\hline Total anthocyanin & -0.577 & 0.487 \\
\hline
\end{tabular}

Note. ${ }^{\text {a }}$ Values of color intensity and hue obtained by the software developed

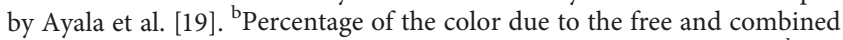
anthocyanins described by Glories. ${ }^{\mathrm{c}}$ Kerenyi and Kampis Index. ${ }^{\mathrm{d}}$ Proportion of total pigment color due to polymeric pigment $\left(\mathrm{CA}_{\mathrm{II}}\right)$

treatments was barely observed for mature wines. This fact points to the high influence of the initial composition of the wines to be treated on the effectiveness of the fiber fining. It is more interesting for the wine industry to modulate the wine composition when grapes are not harvested at their optimal maturity. Thus, the large effect of fining with grape fibers when applied on unripe and overripe wines indicates that this type of treatment could be a good tool for winemakers. Despite this indication, it should be noted that the fining treatment of wines with grape pomace fibers had a slight effect on wine features under winery-like conditions because the observed differences among control and treated wines were very small and almost disappeared after several months of wine ageing. These results seem to limit the actual applicability of this type of fining treatment by the wine industry. However, considering previous studies by other authors under laboratory conditions, it should be noted that the effect of treatments may be improved by the application of higher doses of fibers $[1,9,10]$, by trying other cultivars for obtaining fibers $[8,9,14]$, or by using fresh grapes instead of grape pomaces for obtaining fibers [9]. In this way, it could be interesting to use the grape solid wastes from white wine winemaking in order to obtain cell wall material from nonfermented grapes by reusing winery wastes instead of commercially valuable fresh grapes. In view of all of these results, further studies are required to optimize the effectiveness of fining wines with grape pomace fibers before proposing their use by commercial wineries at an industrial scale.

\section{Conflicts of Interest}

The authors declare that they have no conflicts of interest.

\section{Acknowledgments}

The authors would like to thank American Journal Experts for proofreading the manuscript and providing help with language. This work was supported by CONICYT-Chile (FONDECYT postdoctoral project no. 3150322, FONDECYT grant no. 1140882, and FONDECYT grant no. 11160510).

\section{References}

[1] A. B. Bautista-Ortín, M. Cano-Lechuga, Y. Ruiz-García, and E. Gómez-Plaza, "Interactions between grape skin cell wall material and commercial enological tannins. Practical implications," Food Chemistry, vol. 152, pp. 558-565, 2014.

[2] K. A. Bindon and J. A. Kennedy, "Ripening-induced changes in grape skin proanthocyanidins modify their interaction with cell walls," Journal of Agricultural and Food Chemistry, vol. 59, no. 6, pp. 2696-2707, 2011.

[3] K. Bindon, P. Smith, H. Holt, and J. Kennedy, "Interaction between grape-derived proanthocyanidins and cell wall material. 2. Implications for vinification," Journal of Agricultural and Food Chemistry, vol. 58, no. 19, pp. 10736-10746, 2010.

[4] K. Bindon, P. Smith, and J. Kennedy, "Interaction between grape-derived proanthocyanidins and cell wall material. 1. Effect on proanthocyanidin composition and molecular mass," Journal of Agricultural and Food Chemistry, vol. 58, no. 4, pp. 2520-2528, 2010.

[5] R. L. Hanlin, M. Hrmova, J. F. Harbertson, and M. O. Downey, "Review: condensed tannin and grape cell wall interactions and their impact on tannin extractability into wine," Australian Journal of Grape and Wine Research, vol. 16, no. 1, pp. 173-188, 2010.

[6] J. M. Hernández-Hierro, N. Quijada-Morín, L. MartínezLapuente et al., "Relationship between skin cell wall composition and anthocyanin extractability of Vitis vinifera L. cv. Tempranillo at different grape ripeness degree," Food Chemistry, vol. 146, no. 1, pp. 41-47, 2014.

[7] N. Quijada-Morín, J. M. Hernández-Hierro, J. C. Rivas-Gonzalo, and M. T. Escribano-Bailón, "Extractability of low molecular mass flavanols and flavonols from red grape skins. relationship to cell wall composition at different ripeness stages," Journal of Agricultural and Food Chemistry, vol. 63, no. 35, pp. 7654-7662, 2015.

[8] A. B. Bautista-Ortín, Y. Ruiz-García, F. Marín, N. Molero, R. Apolinar-Valiente, and E. Gómez-Plaza, "Remarkable proanthocyanidin adsorption properties of monastrell pomace cell wall material highlight its potential use as an alternative fining agent in red wine production," Journal of Agricultural and Food Chemistry, vol. 63, no. 2, pp. 620-633, 2015.

[9] K. Bindon and P. Smith, "Comparison of the affinity and selectivity of insoluble fibres and commercial proteins for wine proanthocyanidins," Food Chemistry, vol. 136, no. 2, pp. 917-928, 2013.

[10] R. F. Guerrero, P. Smith, and K. Bindon, "Application of Insoluble Fibers in the Fining of Wine Phenolics," Journal of Agricultural and Food Chemistry, vol. 61, no. 18, pp. 44244432, 2013.

[11] P. Ribéreau-Gayon, Y. Glories, A. Maujean, and D. Dubourdieu, "Clarification and stabilization treatments: fining wine," in Handbook of Enology Volume 2: The Chemistry of Wine and Stabilization and Treatments, pp. 301-331, John Wiley \& Sons, Chinchester, UK, 2nd edition, 2006. 
[12] C. Maury, P. Sarni-Manchado, S. Lefebvre, V. Cheynier, and M. Moutounet, "Influence of fining with plant proteins on proanthocyanidin composition of red wines," American Journal of Enology and Viticulture, vol. 54, no. 2, pp. 105-111, 2003.

[13] A. B. Bautista-Ortín, A. Martínez-Hernández, Y. Ruiz-García, R. Gil-Muñoz, and E. Gómez-Plaza, "Anthocyanins influence tannin-cell wall interactions," Food Chemistry, vol. 206, pp. 239-248, 2016.

[14] A. B. Bautista-Ortín, N. Molero, F. Marín, Y. Ruiz-García, and E. Gómez-Plaza, "Reactivity of pure and commercial grape skin tannins with cell wall material," European Food Research and Technology, vol. 240, no. 3, pp. 645-654, 2015.

[15] International Organisation of Vine and Wine, Compendium of International Methods of Wine and Must Analysis, International Organisation of Vine and Wine, Paris, France, 2016.

[16] P. Ribéreau-Gayon, D. Dubordieu, B. Donèche, and A. Lonvaud, "Red winemaking," in Handbook of Enology Volume 1: The Microbiology of Wine and Vinifications, pp. 326-395, John Wiley \& Sons, Chinchester, UK, 2nd edition, 2006.

[17] R. Apolinar-Valiente, I. Romero-Cascales, J. M. López-Roca, E. Gómez-Plaza, and J. M. Ros-García, "Application and comparison of four selected procedures for the isolation of cell-wall material from the skin of grapes cv. Monastrell," Analytica Chimica Acta, vol. 660, no. 1-2, pp. 206-210, 2010.

[18] P. Ribéreau-Gayon, Y. Glories, A. Maujean, and D. Dubourdieu, "Phenolic compounds," in Handbook of Enology Volume 2: The Chemistry of Wine and Stabilization and Treatments, pp. 141203, John Wiley \& Sons, Chinchester, UK, 2nd edition, 2006.

[19] F. Ayala, J. F. Echávarri, and A. I. Negueruela, "MSCV ${ }^{\circledR, " ~}$ 2014, http://www.unirioja.es/color/descargas.shtml.

[20] J. L. Pastor del Rio and J. A. Kennedy, "Development of procyanidins in Vitis vinifera L. cv. Pinot noir grapes and extraction into wine," American Journal of Enology and Viticulture, vol. 57, no. 2, pp. 125-132, 2006.

[21] J. A. Kennedy and G. P. Jones, "Analysis of proanthocyanidin cleavage products following acid-catalysis in the presence of excess phloroglucinol," Journal of Agricultural and Food Chemistry, vol. 49, no. 4, pp. 1740-1746, 2001.

[22] M. Fanzone, A. Peña-Neira, M. Gil, V. Jofré, M. Assof, and F. Zamora, "Impact of phenolic and polysaccharidic composition on commercial value of Argentinean Malbec and Cabernet Sauvignon wines," Food Research International, vol. 45, no. 1, pp. 402-414, 2012.

[23] Y. Glories, "La couleur des vins rouges. 2éme partie: Mesure, Origine et Interpretation," Connaissance de La Vigne et Du Vin, vol. 18, no. 4, pp. 253-271, 1984.

[24] A. I. Negueruela, J. F. Echavarri, and M. M. Perez, "A Study of correlation between enological colorimetric indexes and CIE colorimetric parameters in red wines," American Journal of Enology and Viticulture, vol. 46, no. 3, pp. 353-356, 1995.

[25] F. J. Heredia, A. M. Troncoso, and M. Guzmán-Chozas, "Multivariate characterization of aging status in red wines based on chromatic parameters," Food Chemistry, vol. 60, no. 1, pp. 103-108, 1997.

[26] R. Canals, M. C. Llaudy, J. Valls, J. M. Canals, and F. Zamora, "Influence of ethanol concentration on the extraction of color and phenolic compounds from the skin and seeds of tempranillo grapes at different stages of ripening," Journal of Agricultural and Food Chemistry, vol. 53, no. 10, pp. 40194025, 2005.

[27] M. Gil, N. Kontoudakis, E. González et al., "Influence of grape maturity and maceration length on color, polyphenolic composition, and polysaccharide content of Cabernet
Sauvignon and Tempranillo wines," Journal of Agricultural and Food Chemistry, vol. 60, no. 32, pp. 7988-8001, 2012.

[28] M. S. García-Falcón, C. Pérez-Lamela, E. Martínez-Carballo, and J. Simal-Gándara, "Determination of phenolic compounds in wines: influence of bottle storage of young red wines on their evolution," Food Chemistry, vol. 105, no. 1, pp. 248-259, 2007.

[29] M. Monagas, C. Gómez-Cordovés, and B. Bartolomé, "Evolution of the phenolic content of red wines from Vitis vinifera L. during ageing in bottle," Food Chemistry, vol. 95, no. 3, pp. 405-412, 2006.

[30] F. He, N. N. Liang, L. Mu et al., "Anthocyanins and their variation in red wines II. Anthocyanin derived pigments and their color evolution," Molecules, vol. 17, no. 2, pp. 1483-1519, 2012.

[31] L. Zeng, P. L. Teissèdre, and M. Jourdes, "Structures of polymeric pigments in red wine and their derived quantification markers revealed by high-resolution quadrupole timeof-flight mass spectrometry," Rapid Communications in Mass Spectrometry, vol. 30, no. 1, pp. 81-88, 2016.

[32] T. Doco, N. Quellec, M. Moutounet, and P. Pellerin, "Polysaccharide patterns during the aging of Carignan noir red wines," American Journal of Enology and Viticulture, vol. 50, no. 1, pp. 25-32, 1999.

[33] M. Gil, M. Quiros, F. Fort et al., "Influence of grape maturity and maceration length on polysaccharide composition of cabernet sauvignon red wines," American Journal of Enology and Viticulture, vol. 66, no. 3, pp. 393-397, 2015. 


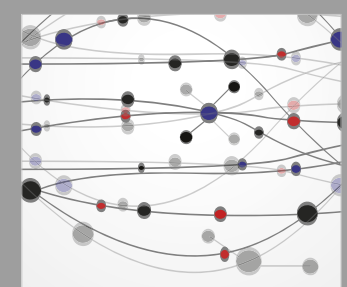

The Scientific World Journal
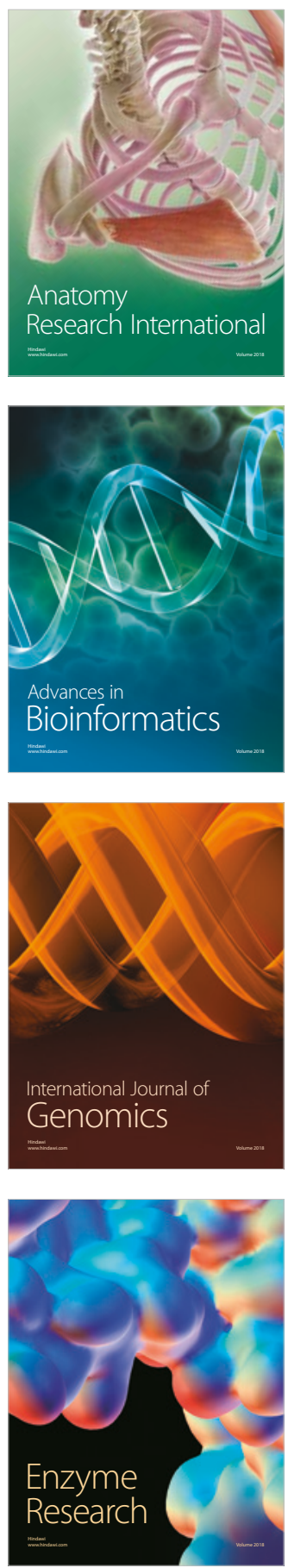
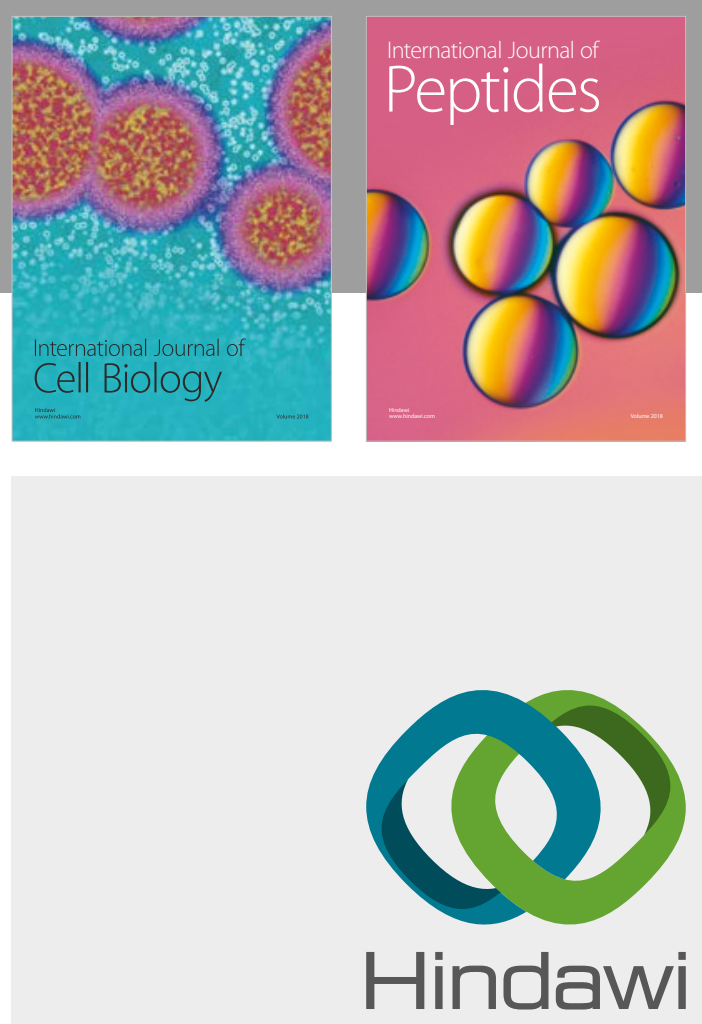

Submit your manuscripts at

www.hindawi.com
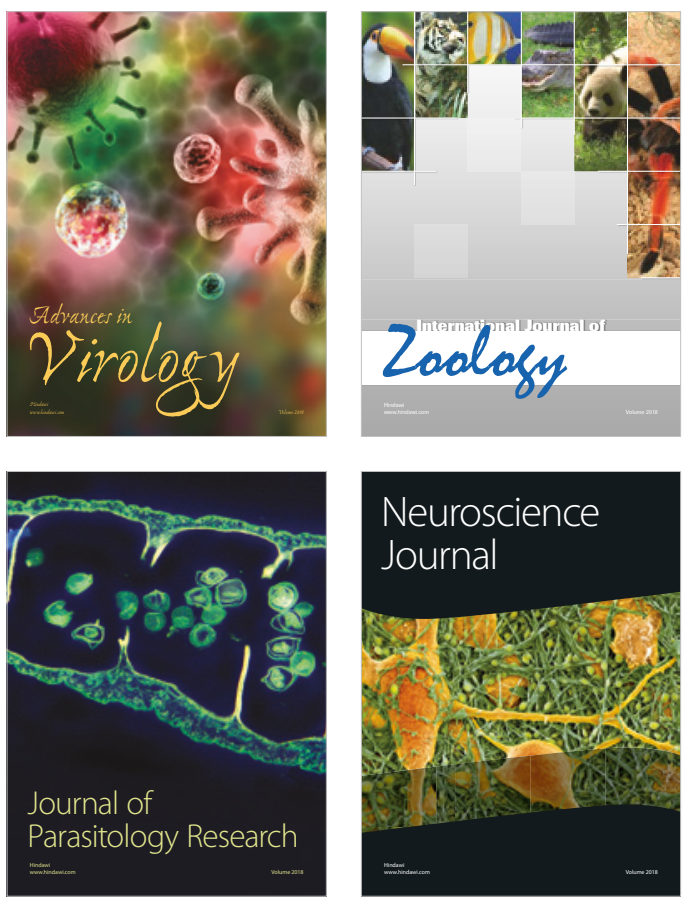
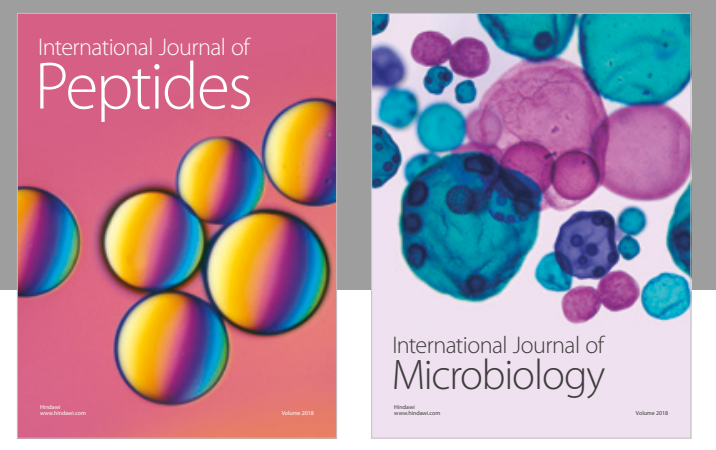

nternational Journal of Microbiology
Journal of
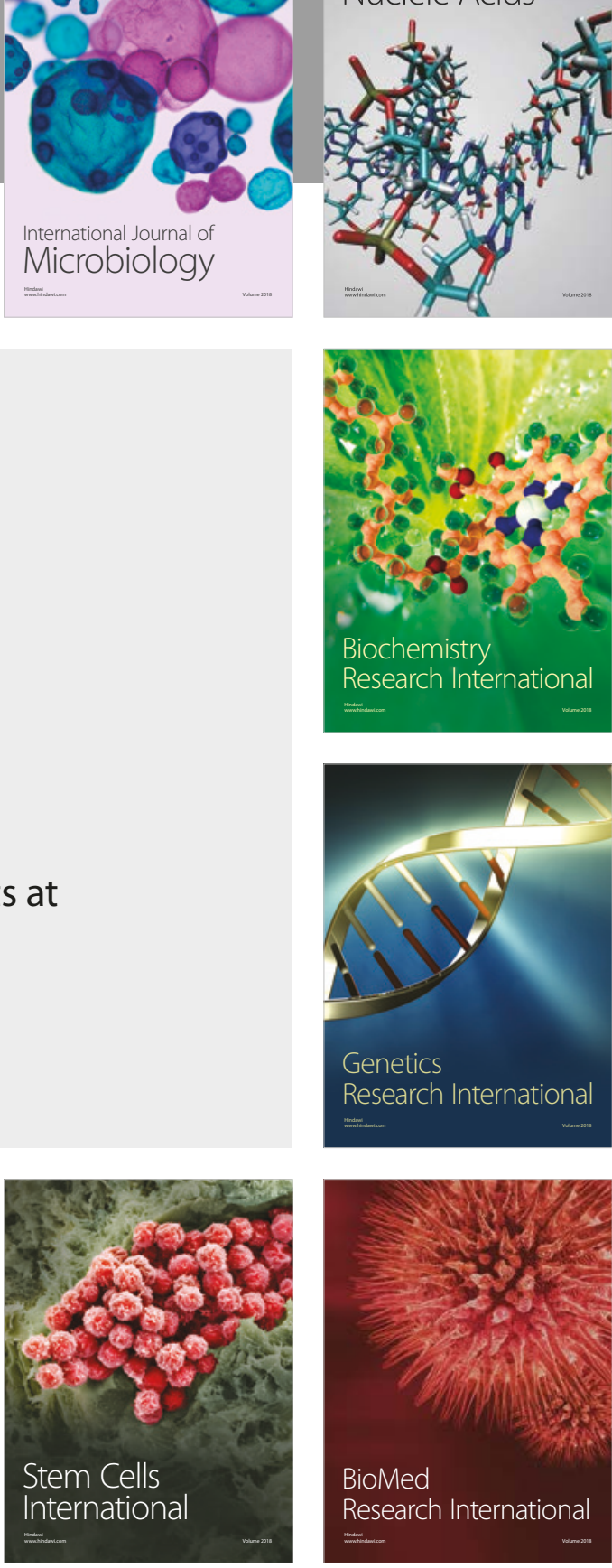
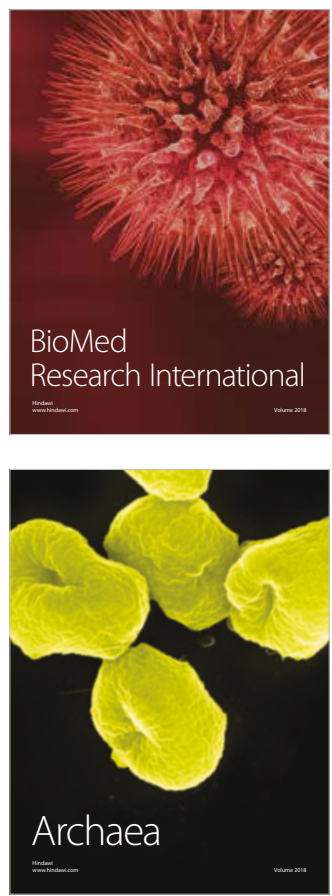